\title{
Youth, Alcohol, and Speeding: Their Joint Contribution to Highway Accidents
}

prepared by

PAUL W. FINGERMAN, JERROLD M. LEVINE, and ELLEN J. EISNER

prepared for the U.S. Department of Transportation,

National Highway Traffic Safety Administration, Washington, D.C. 20590

Contract No.: DOT-HS-5-01210

September 1976

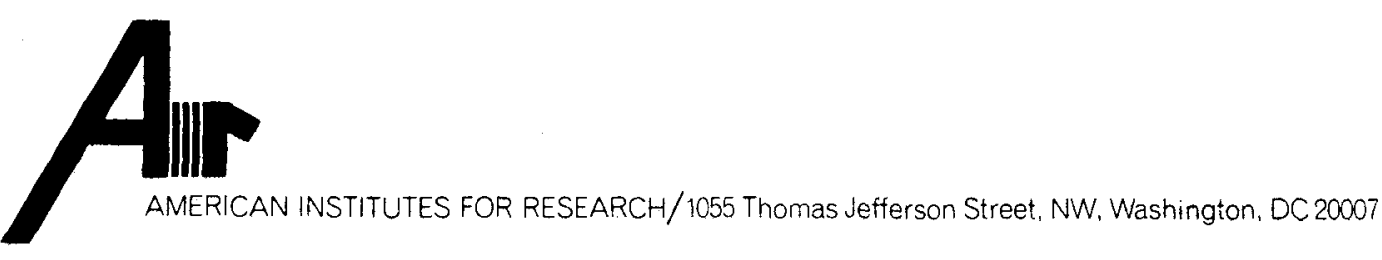


Prepared for the Department of Transportation, National Highway Traffic Safety Administration under Contract No.: DOT-HS-5-01210. The opinions, findings, and conclusions expressed in this publication are those of the authors and not necessarily those of the: National Highway Traffic Safety Administration. 
AIR-52300-9/76-FR

YOUTH, ALCOHOL, AND SPEEDING:

THEIR JOINT CONTRIBUTION TO HIGHWAY ACCIDENTS

Prepared by:

Paul W. Fingerman

Jerrold M. Levine

Ellen J. Eisner

Prepared for:

U. S. Department of Transportation

National Highway Traffic Safety Administration

Washington, D. C. 20590

Contract No. DOT-HS-5-01210

September 1976 
Techaical Repert Docusentetion Page

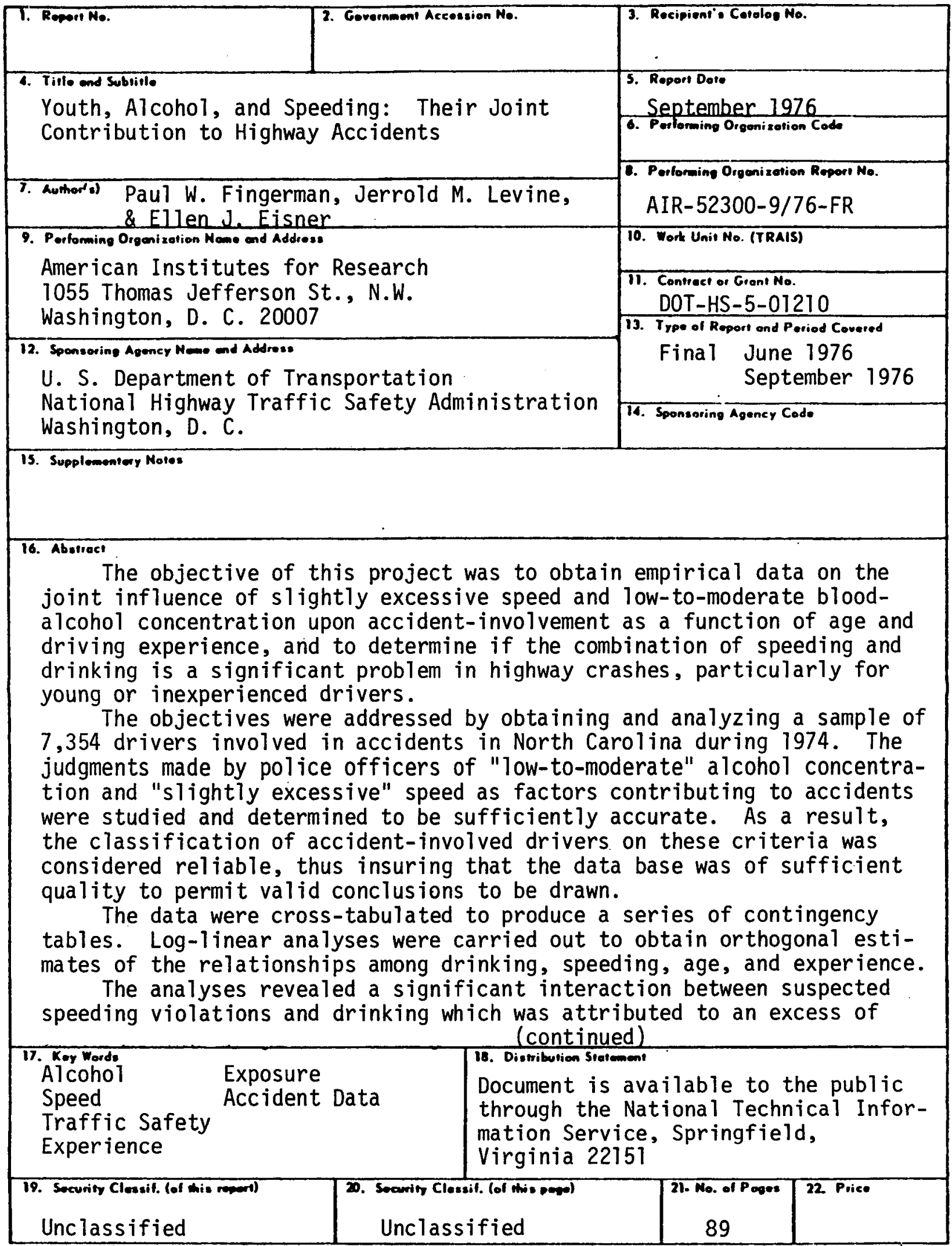

Form DOT F 1700.7 (8-72)

Reproduction of completed poge outhorized 
Abstract (Cont'd)

accidents involving both speeding and drinking. There was also a significant interaction between speed-prior-to-impact and drinking, due to an excess of drinking accidents above $46 \mathrm{mph}$. While both of these interactions were statistically reliable, the combination, speed-and-drinking, was found for only 2.5 to $3.5 \%$ of sampled drivers, involved in 1.5 to $2.0 \%$ of the sampled accidents.

Drivers judged culpable for their accidents also showed an interaction between speed-prior-to-impact and drinking, but did not demonstrate a significant interaction between suspected speeding violation and drinking. There was no difference in the speeding violation-drinking interaction as a function of driver age. However, the interaction of drinking and speed-prior-to-impact did change as a function of age. Inspection of the data revealed that young drivers had an excess of drinking accidents at speeds above $46 \mathrm{mph}$, while older drivers had an excess of drinking accidents at speeds between 25 and $45 \mathrm{mph}$, as well as above $46 \mathrm{mph}$. There was no evidence that the speeding-drinking combination posed a special problem for young drivers.

There was no change in the speeding-drinking relationship as a function of driving experience.

The following recommendations were made. First, there is no basis for a countermeasure targeted precisely at the combination of speedingand-drinking at this time. Second, further study of speeding and drinking among culpable drivers is warranted. Third, further study of speed-priorto-impact, especially as it relates to other factors such as time of day, type of road, and traffic conditions, is warranted, since it may lead to the development of improved alcohol countermeasures targeted at particular age segments of the driving population. Fourth, in future research concerned with prior driving experience, consideration should be given to the precise definition (in terms of years of driving) of experienced and inexperienced drivers. 
TABLE OF CONTENTS

Page

ACKNOWLEDGEMENTS .............................. vi

SUMMARY ...........................

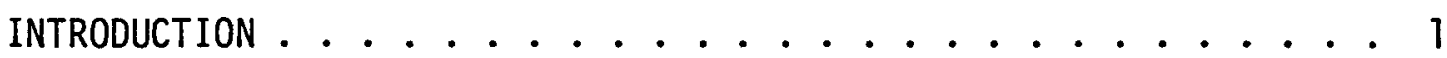

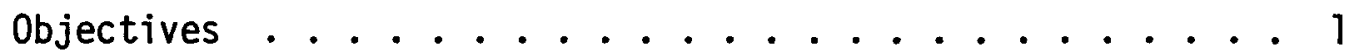

Background ................. 1

Data Source .................. 2

Data Characteristics ............. 3

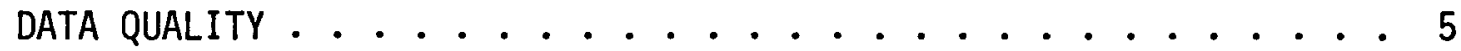

Policies and Procedures .............. 5

Training and Experience of Data Collectors ....... 6

Empirical Estimation of Validity . . . . . . . . . 7

EXPERIMENTAL DESIGN AND ANALYTICAL PLAN . . . . . . 17

Sampling Plan ................. 17

Independent Variables . . . . . . . . . . . . . 21

Design and Analysis ................... 21

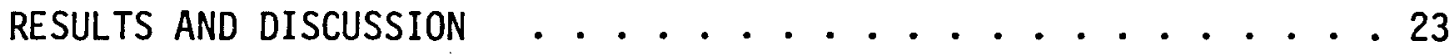

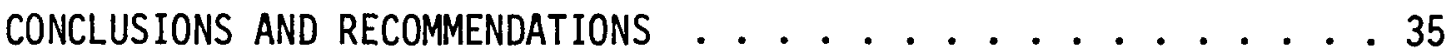

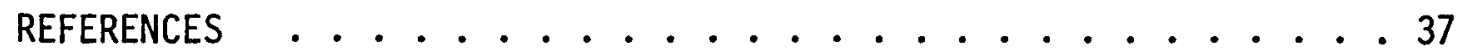

APPENDIX A - Additional Driver Frequency Contingency Tables . . . 39

APPENDIX B - Additional Log-Linear Analys is Summary Tables . . . 45

APPENDIX C - North Carolina Accident Report Form . . . . . . 51

APPENDIX D - Sample Materials From Data Quality Studies . . . . 55

APPENDIX E - Auxiliary Results ............ . 73

APPENDIX F - Detailed Crosstabulations ......... 77 
Table 1 - List of Indicators Which May Enable Police: to Judge That a Driver in an Accident Had Been Drinking

Table 2 - List of Indicators Which May Enable Police to Judge Excessive Speed in an Accident ....... 11

Table 3 - Ranked Importance and Confidence in Drinking Indicators ............... 12

Table 4 - Ranked Importance and Confidence in Speed Indicators ............. 14

Table 5 - Distribution of Responses in Accident Sceriarios as a Function of Driver Age ......... 16

Table 6 - Driver Frequency Contingency Table for All Accident-Involved Drivers . . . . . . . 24

Table 7 - Driver Frequency Contingency Table for Culpable Drivers ............. 25

Table 8 - Log-Linear Analysis Summary Table for All Accident-Involved Drivers ......... 26

Table 9 - Log-Linear Analys is Sumary Table for Culpable Drivers ............. 27

Table 10 - Expected and Obtained Percentages of All Accident-Involved Drivers as a Function of Speeding and Drinking ............ 28

Table 11 - Expected and Obtained Percentages of A11 Accident-Involved Drivers as a Function of Speed-Prior-to-Impact and Drinking ...... 30

Table 12 - Summary of Primary Results .......... 33 


\section{LIST OF FIGURES}

Page

Figure 1. Procedure for selecting the sample ....... 18

Figure 2. Generation of analytical subsamples ...... 19

Figure 3. Interaction of speed-prior-to-impact with drinking as a function of age for all accidentinvolved drivers .............. 32 


\section{ACKNOWLEDGEMENTS}

The authors wish to express their gratitude to those individuals and organizations who assisted in the performance of this research. Mr. Kenneth N. Cates, Coordinator of Planning for the North Carolina Division of Motor Vehicles provided invaluable support for all phases of the project, and, in particular, in obtaining and analyzing the accident and driver experience data. Superintendent Thomas S. Smith and Lt. James Harvey of the Maryland State Police and Colonel Edward Jones of the North Carolina Highway Patrol assisted us in the study of accident investigator judgments of drinking and speeding. Finally, we would like to thank Mr. Steven Levy and Dr. Marvin Levy of the National Highway Traffic Safety Administration, for their guidance and support throughout the project. 


\section{SUMMARY}

The objective of this project was to obtain empirical data on the joint influence of slightly excessive speed and low-to-moderate bloodalcohol concentration upon accident-involvement as a function of age and driving experience, and to determine if the combination of speeding and drinking is a significant problem in highway crashes, particularly for young or inexperienced drivers.

The objectives were addressed by obtaining and analyzing a sample of 7,354 drivers involved in accidents in North Carolina during 1974. The judgments made by police officers of "low-to-moderate" alcohol concentration and "slightly excessive" speed as factors contributing to accidents were studied and determined to be sufficiently accurate. As a result, the classification of accident-involved drivers on these criteria was considered reliable, thus insuring that the data base was of sufficient quality to permit valid conclusions to be drawn.

The data were cross-tabulated to produce a series of contingency tables. Log-linear analyses were carried out to obtain orthogonal estimates of the relationships among drinking, speeding, age, and experience.

The analyses revealed a significant interaction between suspected speeding violations and drinking which was attributed to an excess of accidents involving both speeding and drinking. There was also a significant interaction between speed-prior-to-impact and drinking, due to an excess of drinking accidents above $46 \mathrm{mph}$. While both of these interactions were statistically reliable, the combination, speed-and-drinking, was found for only 2.5 to $3.5 \%$ of sampled drivers, involved in 1.5 to $2.0 \%$ of the sampled accidents.

Drivers judged culpable for their accidents also showed an interaction between speed-prior-to-impact and drinking, but did not demonstrate a significant interaction between suspected speeding violation and drinking.

There was no difference in the speeding violation-drinking interaction as a function of driver age. However, the interaction of drinking and speed-prior-to-impact did change as a function of age. Inspection of the data revealed that young drivers had an excess of drinking accidents at speeds above $46 \mathrm{mph}$, while older drivers had an excess of drinking accidents at speeds between 25 and $45 \mathrm{mph}$, as well as above $46 \mathrm{mph}$. There was no evidence that the speeding-drinking combination posed a special problem for young drivers.

There was no change in the speeding-drinking relationship as a function of driving experience. 
The following recommendations were made:

There is no basis for a countermeasure targeted precisely at the combination of speeding-and-drinking at this time.

Further study of speeding and drinking among culpable drivers is warranted.

Further study of speed-prior-to-impact, especially as it relates to other factors such as time of day, type of road, and traffic conditions, is warranted, since it may lead to the development of improved alcohol countermeasures targeted at particular age segments of the driving population.

In future research concerned with prior driving experience, consideration should be given to the precise definition (in terms of years of driving) of experienced and inexperienced drivers. 


\section{INTRODUCTION}

To develop effective countermeasures, it is important to understand the factors which contribute to automobile accidents. While a complete model of accidents is not technically feasible at present, adequate understanding of individual or small sets of contributing factors could lead to countermeasures targeted precisely at particularly potent factors. In many cases factors are uncovered which show strong statistical associations to accidents, even though causal linkages have not yet been established. Research is needed to clarify the relationships of such factors to accidents, so that specific countermeasures may be developed which will reduce the frequency of accidents associated with these factors.

\section{Objectives}

Highway accidents are the single largest cause of death among youths between the ages of 15 and 24 years. Preusser, 0ates, and Orban (1975) speculated that the joint occurrence of slightly excessive speed and lowto-moderate levels of alcohol in the blood was prominent in crashes involving young drivers. The objective of the present effort was to determine clearly and firmly the relationship among age, alcohol, and speed as factors jointly contributing to highway crashes. In particular, if an accident involves drinking and excessive speed, is the driver more likely to be young ( 24 years old or less) than if the accident involved no speeding and/or drinking? Additional questions to be addressed included whether or not an interaction between speed and alcohol exists (i.e., are speed and alcohol found in accidents more often than would be expected based on the frequency of each individually); whether there is an interaction among experience, speed, and alcohol; whether the culpability of the driver in question impacts on these interactions; and, how adjustment for exposure affects the conclusions drawn from the above questions.

\section{Background}

The interaction of driver age and alcohol is well established (see Preusser, Dates, \& Orban, 1975, for a recent review). The interaction of driver age and speed has been studied by at least one team of investigators (Filkins, Clark, Rosenblatt, Carlson, Kerlan, \& Manson, 1970) who found that fatally injured young drivers were typically driving faster than fatally injured older drivers. Only one published report has appeared on the combined effects of age, alcohol, and speed. White and clayton (1972) examined 30,479 male drivers involved in accidents which occurred on rural North Carolina highways with speed limits between 50 and 60 miles per hour. They classified each driver according to age, drinking, and speed prior to impact. A reanalysis of their data showed a significant interaction of age, alcohol, and speed. However, several factors limit the usefulness of this study. First, by sampling only male drivers, good 
weather accidents, and locations with high speed limits, the genera]izability of the findings is limited. Second, the restrictions on the data. collected do not permit one to investigate the reason for the interaction.

Two hypotheses have been put forth to account for such interactions. The first suggests that alcohol, as a psychoactive drug which releases the user from normal inhibitory controls, is a particular danger to young (immature?) drivers; their release from inhibition results in speeding. Presumably, older (mature?) drivers are less likely to react to alcohol with speeding behavior. The second hypothesis proposes that one must learn to drink, just as one learns to drive. The problem for young drivers is that they are learning to do both simultaneausly, and their inexperience at both tasks leads to accidents. The experienced driverdrinker, for example, may have learned to slow down when driving after drinking, and thus avoid accidents.

\section{Data Source}

Initial efforts were primarily devoted to selecting a source of accident data which would allow the issues described above to be analytically addressed. Thus, the source had to supply, at a minimum, driver age, whether or not he had been drinking prior to the accident, whether or not he was speeding prior to the accident, how lang the driver had been driving, and whether or not he was culpable. Further, since low-tomoderate BAC levels were of interest, an arrest for "driving under the influence" was not an acceptable indicator for drinking since the usual presumptive level for such a charge is .10\%, while levels as low as $.05 \%$ seem to make drivers prone to accidents (especially young drivers--c.f. Preusser et al., 1975). Similarly, formal charges pilaced against a driver for "exceeding the speed 1imit" or "driving too fast: for conditions" were too restrictive a criterion to be used as an indicatior of speed. Since collecting specific supplementary data on a new sample of accidents would have been a relatively expensive undertaking, our search for a data source focused on states whose normal accident reporting procedures would provide the necessary data. As an additional criterion, a state was sought which collected its records statewide into a central reporting system, preferably computerized, so that sampling procedures could be readily implemented.

The state of North Carolina was found to have central accident record systems with the necessary data. The North Carolina Division of Motor Vehicles maintains an automated accident data file consisting of information transcribed and/or reduced from a uniform report used statewide by all police agencies to report all accidents involving a fatality, personal injury, or property damage of over $\$ 200$, and not occurring totaliy on private property. 1 This file contains data for all but one of the

Actually, all accidents reported to the Division are included in the file, but this study will be limited to those described above, which are required by law to be reported. A copy of the report form is included in Appendix $\mathrm{C}$. 
necessary variables and allows a cross-reference to another file which contains the remaining one. Each accident report contains driver age at the time of the accident. In addition, each driver is judged by the officer at the scene as to his sobriety. This data is collected for statistical purposes, and is independent of any alcohol-related charges made. The officer uses one of four codes: "had not been drinking," "drinking--ability impaired," "drinking--unable to determine impairment," and "unknown."

For each of 121,681 drivers of "vehicle one" in reportable accidents for 1974, 81.9\% were judged "had not been drinking," 5.1\% "drinking-ability impaired," 6.0\% "drinking--unable to determine impairment," $4.5 \%$ "unknown," and in $2.5 \%$ of the reports, no code was entered. Thus, in 93\% of these cases, an unambiguous judgment of drinking was available; similar unambiguous judgments were available for $90.1 \%$ of the "vehicle two" drivers involved in two-or-more vehicle accidents.

Information on vehicle speed-prior-to-impact is also contained on the form. First, the actual speed of each vehicle is estimated from evidence at the scene and recorded. Then, based on this estimate, road, traffic and weather conditions, and any other relevant factors, the investigating officer indicates whether or not an "excessive speed" violation is indicated for each involved driver. This "violation-indicated" rarely results in actual charges, since the violation is usually inferred rather than recorded (via radar, etc.), and is collected for statistical and research purposes.

Culpability may be assessed for many accidents by inference. The report indicates whether traffic charges were placed against each of the involved drivers. By considering only those accidents in which a single driver was charged, one may obtain a sample of culpable drivers.

Driving experience is not recorded directly on the accident report form. However, using identifying information from the form, it is possible to retrieve this information from another automated file maintained by the Division of Motor Vehicles, the Driver Record File. This file contains the date-of-issue of the original operator's license for each driver, and whether he has held out-of-state licenses prior to the issuance of a North Carolina license. Thus, driving experience information, in terms of time-with-a-driving-license, is available for most accidentinvolved drivers. 2

Data Characteristics

The preceding discussion on the source of accident data considered the identification of a data base containing the information necessary

\footnotetext{
Date of first issue has been consistently recorded only since 1973. Thus, for accidents which occurred in 1974, driving experience greater and less than one year may be reliably discriminated.
} 
and sufficient for the study of youth, alcohol, and speeding, but was quite glib with respect to one very important point; the quality of the data. Inferences from this study have to do with drivers and the events surrounding their accidents, but the data themselves were obtained from accident reports. Thus, the investigating officer stands as a crucial intervening agent between the actual occurrences and the data utilized. It is not sufficient merely to assume that he is a neutral agent. At best, he probably makes errors which add noise to the data; at worst, he has systematic biases which relate to the variables of interest and which may act to filter the data in important ways. For this reason, a major activity of the project was to examine the quality of the data, particularly with respect to how well the investigating officer transmits the actual occurrences at the accident scene. 


\section{DATA QUALITY}

Three major areas were isolated as potentially important to the quality of the accident data contained in any centralized reporting system. They were:

(1) Policies and procedures prescribed by cognizant agencies for the collection and handling of accident data;

(2) Training and experience of data collectors, particularly for any judgments or "expert opinions" which are required; and

(3) Empirical estimation of data validity and sources of bias.

Each of these topics is discussed below as it refers to the North Carolina data collection system.

\section{Policies and Procedures}

Regardless of the format for data collection, there is always the possibility that the policies and procedures of an agency regarding accident investigation may seriously constrain the gathering of information. For example, in Maryland it is the policy of the Department of Motor Vehicles that the information on driver condition (e.g., "had been drinking") be collected for statistical purposes and reflect the officer's expert opinion, whether or not sufficient evidence exists for an arrest. The Maryland State Police subscribe to this policy, and pass it on to State Police officers in the course of training. However, the procedures in some local agencies (e.g., county police) are not consistent with this policy: Officers are sometimes instructed not to check "had been drinking" unless an alcohol arrest is made. These restrictive policies would suggest that the data supplied by some agencies in Maryland are not comparable to others.

On the other hand, accident investigation in North Carolina is subject to more central control. Standards for training and procedures for investigations are primarily set by the Highway Patrol and the Division of Motor Vehicles. Their policy on reporting the data elements of interest to us is unconstrained, and the use of judgment in accident investigation is cultivated. Further, a primary responsibility of the Highway Patrol itself is the investigation of accidents, and they investigate almost half of the crashes which occur in North Carolina. Thus, they directly supply about half of the accident data in the state's computerized system. 
Not only are the drinking data from North Carolina collected according to the relaxed criteria established for this study, but the same is true for speeding. In North Carolina the investigating officer has a list of possible "violations indicated," including excessive speed, and he simply checks as many as he judges relevant to each driver. Further, accident investigators are required to estimate the speed-prior-to-impact of all accident-involved vehicles.

\section{Training and Experience of Data Collectors}

All new recruits to the North Carolina Highway Patrol receive their training at a central location. They receive 48 hours of classroom instruction in accident investigation, plus approximately 10 additional hours of practical instruction. The course is based on Baker's Northwestern University Traffic Institute text (Baker, 1963), and follows his philosophy in genera1. Heavy emphas is is placed on understanding the etiology of crashes, and the course deals with determining causative factors. Substantial training is provided in the estimation of speed-prior-to-impact, the measurement of skid marks, post-crash vehicle path, collision damage, and the use of speed-drag nomographs. Some attention is given in the accident course to drinking drivers, particularly on detection of alcohol during post-crash interrogation (via motor and speech cues, driver affect, and odor). In addition, new recruits receive a separate, five-hour, alcohol investigation course which is specifically aimed at detecting intoxicated drivers. The focus of this training is to identify drinking drivers as well as to determine if they are legally "driving under the influence." Troopers interviewed indicated that removing a drinking driver from the road (via arrest or threat of arrest) is part of their job whether or not a conviction is obtained.

The Highway Patrol also provides an in-service training program to its troopers which serves both to refresh earlier training, and to provide older officers with training materials introduced to the new-recruit course after their graduation. For example, the use of speed nomographs was introduced into the accident investigation course about seven years ago. Shortly thereafter, the Patrol proyided in-service training on nomographs to its troopers in the field. ${ }^{3}$

${ }^{3}$ Training is similar, though sometimes not as intensive, for most municipal police departments in the state. The city police, together with the Highway Patrol, handle $99.4 \%$ of the accident investigations. We believe that the Highway Patrol probably supplies, on the average, the highest quality data, and had originally planned to study only Patrol-investigated accidents. However, $82.4 \%$ of the accidents they investiglate occur in rural areas, while, statewide, only $40.7 \%$ of the accidents occur in rural areas. Thus, to avoid a serious rural bias, it was decided to include data from other agencies (e.g., city police). This may have decreased slightly the overall level of data quality, as a trade-off against better representation of the full accident population. 
Empirical Estimation of Validity

The material provided above indicates that on the basis of face validity, the accident data obtained from North Carolina is of sufficient quality to be used in the study of youth, alcohol, and speed. Empirical validity is discussed in this section. Specifically, two questions are addressed (1) Are police investigator judgments of alcohol and speed involvement accurate? (2) Are judgments concerning the involvement of alcohol in highway crashes biased with regard to the age of the drivers involved? Satisfactory answers to these questions were necessary prerequsites to the interpretation of any relationship among alcohol, speed, and age as contributing factors to highway crashes. To the extent that judgments of speed and alcohol involvement were not accurate, then it was questionable whether an evaluation of the data should have been carried out. If accomplished, certainly any interpretations drawn would have to be carefully qualified. If a judgmental bias with regard to age was found to exist, then either qualifications of interpretations would have to be made or an estimate of such bias be secured and the accident data relating to alcohol involvement adjusted in order to eliminate the age bias statistically.

The highway safety literature has little to offer in answer to the questions posed. Filkins et al. (1970) compared police estimates of drinking involvement with actual blood alcohol levels for driver fatalities in the state of Michigan. They found that of the reports marked "had been drinking" the police were incorrect in only $15 \%$ of the cases (i.e., 85\% of the drivers judged "had been drinking" had non-zero BAC levels). The discrepancy was greater for those checked "had not been drinking." The police were incorrect in $47 \%$ of those cases. In addition, $35 \%$ of those drivers judged "had not been drinking" had BAC levels of $0.10 \%$ or greater. Where the police checked "not known if drinking," 69\% actually were drinking, and $63 \%$ had blood alcohol concentrations greater than $0.10 \%$. It is important to note in this study that police estimates were made only for fatally injured drivers. Thus, many of the cues that are often available, such as those involving motor behavior, were not available in many of these police estimates. Further, it is unknown if the errors made by police involved primarily drivers with very low BAC levels. Twenty-two drivers in the sample had actual BACs of .01-.04\%, and are included among the 34 cases (47\%) of police "misses." These facts may account for the low accuracy of judgment in several of the drinking categories judged.

Carlson (1972) had a team of scientists randomly stop and interview drivers and then test these drivers for blood alcohol concentration. No accidents were involved in this study nor were judgments made by police personnel. Carlson found that $85 \%$ of the time that drivers were judged not to have been drinking, they in fact demonstrated a $0.0 \%$ blood alcohol concentration. On the other hand, $56 \%$ of the drivers who proved to have a blood alcohol concentration greater than $0.0 \%$ were classified as 
had been drinking. It would appear then that nondrinking drivers are accurately classified as not having been drinking, whereas drivers who had been drinking are so categorized only about half of the time. Judgments of "had been drinking" increased in accuracy with the BAC of drivers as indicated by the finding that $45 \%$ of drivers with BACs ranging between .01 and $.04 \%$ were correctly classified, as were $67 \%$ having BACs between .05 and $.09 \%$, and $80 \%$ having BACs greater than . $10 \%$. Carison pointed out that his scientists had "no prior opportunity to observe suggestions of alcohol such as erratic driving behavior or traffic law violation. It is, therefore, reasonable to expect that properly trained and experienced police officers should be able to subjectively classify drivers more accurately than did our interviewers" (pp. 16-17).

Waller (1971) studied narrative reports of accidents involving fatally injured drivers and found that no matter what the blood alcohol concentration, no mention was made at all about either the presence or absence of alcohol in $20 \%$ of the reports. Further, at all blood alcohol concentrations, there was substantial underestimation of the presence of alcohol. Even at the extraordinarily high range of $.20 \%$ or greater, individuals were reported not to have been drinking 13\% of the time. Here again it should be noted that these were fatally injured drivers and therefore the alcohol involvement cues available to the police investigators were minimal. Further, the requirement of writing alcohol information rather than checking a box or filling in a code number, may have affected reporting levels.

We were unable to identify any studies in the literature relating to the question of the accuracy of judging speed as a contributing factor in accidents.

The overinvolvement of young drivers in alcohol-related crashes is a well-documented statistic. However, the literature does not have much to offer on the question of whether police judgments of alcohol are biased by the age of the driver. Waller (1971) conducted one study on this question. From the narrative descriptions of accidents involving fatally injured drivers, he found that if the concentration of alcohol was low (BAC less than .05\%), the officer was less likely to mention alcohol in the report when the driver was age 60 or older than if the driver was younger. If the alcohol concentration was high, police officers were almost twice as likely to report that a person age 60 or older had not been drinking than he was to make a similar report for drivers between ages 20 and 59 .

In order to provide a better base of information than was obtainable from the literature on the questions of accuracy of judging speed and alcohol involvement, and possible age bias in alcohol judgments, and to obtain data from the jurisdictions of interest in this effort, two empirical studies were undertaken. One study addressed the question of judgmental accuracy of alcohol and speed involvement and the other addressed the question of age bias in the judgment of alcohol involvement. 
Accuracy of Judgments of Alcohol and Speed Involvement. A list of 12 cues, which enable police to judge if the driver in an accident had been drinking, was prepared using accident investigation manuals, interviews with police training personnel, and other consultants. This list, shown in Table 1, consists of commoniy reported pieces of evidence used in the assessment of alcohol involvement. A second list of indicators was similarly derived, representing cues which purportedly enable police officers to judge excessive speed in an accident. This list is presented in Table 2. Police officers were to rank-order each list of indicators from most to least important for judging that a driver involved in an accident had been drinking or had been speeding. The data derived could then be used to determine whether or not officers do in fact use those cues which are commonly accepted to be the most accurate indicators of alcohol or speed involvement.

In a subsequent exercise immediately following the ranking of importance of the two sets of cues, the same police officers provided estimates of the confidence they had in each of the cues being indicative of either speeding or drinking, respectively. Specifically, they were asked how certain they would be about whether a driver had been drinking or had been speeding based exclusively upon evidence from that single cue. The objective was to secure an estimate of the accuracy of judgments concerned with alcohol and speed involvement based upon the officers' subjective confidence in the predictability of each of the cues. Research in human decision-making has repeatedly demonstrated that estimates of subjective confidence are highly correlated with accuracy of judgments. (See, for example, Levine \& Samet, 1973, and Levine, Samet, \& Brahlek, 1974.) It was expected that if police officers' judgments of alcohol and speed involvement were accurate, this would be demonstrated by consistently high rankings being given to the commonly accepted most important cues and by an indication of high degrees of subjective confidence associated with these cues.

Age Bias in the Judgment of Alcohol Involvement. Ten brief scenarios were prepared describing accident situations in a fashion ambiguous with respect to whether the drivers had been drinking. The drivers were all indicated to be age 25 or older. A second set of 10 scenarios was then prepared describing the identical accident situation except that the age of the driver was indicated as being young (16- to 19-years-0ld). Police officers were asked to read several of these scenarios and indicate whether or not, based on the information therein contained, the driver (1) had been drinking and his ability was impaired, (2) had been drinking but ability impairment could not be determined, (3) had not been drinking, or (4) the drinking situation was unknown.

By evaluating the frequency with which drivers in each scenario were categorized as having been drinking or not, as a function of the age characteristics described in the scenario, age bias was assessed. If it appeared that there were significant differences as a function of age, then it would be concluded that a bias did exist. Furthermore, an 


\section{Table 1}

\section{List of Indicators Which May Enable Police to Judge That a Driver in an Accident Had Been Drinking}

Chemical Test (Blood, Breath, Urine)

Driver's Appearance

Smell on Driver's Breath

Smell in Driver's Vehicle

Smell in Other Vehicle to Which Driver was Removed

Incriminating Evidence in Vehicle

Driver Admission

Reports from Other Drivers, Passengers, Witnesses

Affective Behavior of Driver at Accident Scene

Driving Behavior of Driver Prior to Accident

Speech Behavior of Driver

Motor Behavior of Driver 
Table 2

List of Indicators Which May Enable Police to Judge Excessive Speed in an Accident

Extent of Damage to Automobile (Interior \& Exterior)

Extent of Property Damage

Extent of Injuries

Driver Reports

Passenger Reports

Witness Reports

Police Observation Prior to Accident

Expelled Passenger

Path of Vehicle Prior to Impact

Path of Vehicle After Impact

Skid Marks

Location of Accident Debris 
Table 3

Ranked Importance and Confidence in Drinking Indicators

\begin{tabular}{lcc}
\hline \multicolumn{1}{l}{ Indicator } & Mean Rank & Mean Confidence \\
\hline & & \\
Smell on Driver's Breath & 2.63 & $87.71 \%$ \\
Motor Behavior of Driver & 2.66 & $72.00 \%$ \\
Driver's Appearance & 4.29 & $45.57 \%$ \\
Affective Behavior of Driver & 4.89 & $61.00 \%$ \\
Speech Behavior of Driver & 5.86 & $55.86 \%$ \\
Driving Behavior Prior to Accident & 6.57 & $46.86 \%$ \\
Reports from Others & 6.77 & $52.29 \%$ \\
Driver Admission & 7.00 & $80.71 \%$ \\
Smell in Driver's Vehicle & 8.00 & $41.14 \%$ \\
Evidence in Driver's Vehicle & 9.03 & $33.86 \%$ \\
Chemical Test & 10.09 & $65.57 \%$ \\
Smell in Other Vehicle & 10.23 & $28.29 \%$ \\
\hline
\end{tabular}


empirical estimate of the magnitude of this bias would be available with which to adjust the data on alcohol involvement in highway accidents. If no evidence of an age bias in the data were found, there would be no reason to suspect the alcohol judgments made on accident reports filed by police officers. In this case, the accident data base could be analyzed in its existing form.

Method. Participants for the two empirical studies were members of the North Carolina Highway Patrol based in two different parts of the state. Fifteen officers operating in the central portion of the state and 20 officers from the western portion were used. Data was collected from diverse geographical zones in order to include a sampling of officers having investigation experience with diverse kinds of accidents.

Two survey booklets were prepared. The first contained the Indicator Survey and was designed to examine the accuracy of judging speed and alcohol involvement. The second contained the Scenario Survey, designed to detect the presence of an age bias in those judgments. Each scenario booklet contained one version of each of the 10 scenarios, five involving younger drivers and five involving older drivers. The assignment of driver age was randomized in such a way that half of the officers judged a younger driver, and half an older driver, on each scenario. Sample materials are shown in Appendix D.

Results and Discussion. The data collected on indicators of drinking and speeding were encouraging with regard to the quality to be expected in reported accident data. Table 3 contains the mean rank and confidence ratings for each drinking indicator. The indicators ranked highest in importance correspond precisely to those emphasized in recruit training as well as in most standard reference works: smell on the driver's breath and the driver's motor behavior. Officers have particular confidence in the first two as bases for decision-making. This suggests that judgments of alcohol involvement based upon these cues are likely to be accurate.

The parallel data for the speed indicators are presented in Table 4. The rank and confidence values for speed indicators tend to be clustered somewhat toward the middle, suggesting more diversity in the cues officers use. However, the two cues clearly judged most important correspond to those cues considered most reliable; skid marks and officer observation. The rank order of indicators corresponds roughly to the true accuracy of these indicators as judged by experts (e.g., Baker, 1963). The two cues of greatest importance also have very high confidences associated with them suggesting that speed judgments based upon these cues are likely to be accurate.

On the basis of the close agreement among the ranked importance of both alcohol and speed indicators with commonly regarded reliable indicators of drinking and excessive speed, it was concluded that officers indeed make judgments using the most important sources of evidence. The high confidence shown for the important indicators suggests that officers use these indicators accurately to produce sufficiently valid judgments 


\section{Table 4}

Ranked Importance and Confidence in Speed Indicators

\begin{tabular}{lcl}
\hline \multicolumn{1}{l}{ Indicator } & Mean Rank & Mean Confidence \\
\hline Skid Marks & 2.91 & $83.43 \%$ \\
Police Observation & 3.46 & $92.00 \%$ \\
Damage to Vehicle(s) & 4.03 & $65.14 \%$ \\
Path Prior to Impact & 4.83 & $60.71 \%$ \\
Path After Impact & 5.63 & $63.57 \%$ \\
Witness Reports & 5.83 & $60.86 \%$ \\
Property Damage & 6.60 & $60.80 \%$ \\
Location of Debris & 7.46 & $45.14 \%$ \\
Passenger Reports & 8.43 & $43.43 \%$ \\
Injuries & 9.06 & $37.43 \%$ \\
Driver Reports & 9.23 & $31.00 \%$ \\
Expelled Passenger & 10.34 & $24.43 \%$ \\
\hline
\end{tabular}


of alcohol and speed involvement. This conclusion is further supported by comparing the relatively high confidences in individual indicators to the confidence officers have in the actual judgments they record on the accident report form. The average confidence reported by officers in their overall sobriety and speeding judgments seems quite reasonable based on an aggregation of information from many semi-independent cues with moderately high individual confidence ratings. Troopers reported overall confidences of $97.4 \%$ and $91.5 \%$ in their actual accident report judgments of drinking and speeding, respectively.

The data from the scenario study were transformed so as to constitute an arbitrary but rational ordinal scale (i.e., "l" corresponded to "had not been drinking;" "2" corresponded to "unknown;" " 3 " corresponded to "drinking--unable to determine impairment;" and "4" corresponded to "drinking--ability impaired"). The mean judgments for old and young drivers were then compared for each scenario via the $t$-test. of the 10 tests performed, two were marginally significant. On one, older drivers were judged more harshly, while on the other, younger drivers had higher mean judgments. The frequency distribution of responses for all scenarios combined is presented in Table 5.

The overall distribution suggests that young drivers are judged "unknown" more often than older drivers, and that older drivers are judged to have been "drinking" more often than younger drivers. When the two drinking categories and the two nondrinking categories were collapsed, the data appeared to be unbiased with respect to age. We concluded that the sample of officers was not biased toward finding disproportionate drinking among young, accident-involved drivers, since, when presented with identical evidence, they make the same findings for both young and old drivers. Note that this is not necessarily inconsistent with Waller's (1971) findings, since he compared judgments of drivers between 20 and 59 to drivers over 60 .

Data on trooper experience was collected for sample-description purposes. Mean age was 34.3 years, mean time in the Highway Patrol was 10.3 years, and mean prior police experience was 0.9 years. The subjects, in the month prior to testing, investigated an average of 11.0 accidents, made 6.2 drinking arrests, and 36.0 speeding arrests. 


\section{Table 5}

Distribution of Responses in Accident Scenarios as a Function of Driver Age

\begin{tabular}{|c|c|c|c|c|}
\hline \multirow{2}{*}{ Response } & \multicolumn{2}{|c|}{ Overall } & \multicolumn{2}{|c|}{ Collapsed } \\
\hline & Young & 01d & Young & old \\
\hline Had not been drinking & 67 & 70 & \multirow{2}{*}{144} & \multirow{2}{*}{137} \\
\hline Unknown & 77 & 67 & & \\
\hline $\begin{array}{l}\text { Drinking--unable to deter- } \\
\text { mine impairment }\end{array}$ & 25 & 29 & \multirow{2}{*}{31} & \multirow{2}{*}{38} \\
\hline Drinking--ability impaired & 6 & 9 & & \\
\hline
\end{tabular}




\section{EXPERIMENTAL DESIGN AND ANALYTICAL PLAN}

A restricted random sample of accident reports was drawn from among the 138,876 reports contained in the North Carolina Division of Motor Vehicles automated file for the calendar year 1974. The data on accidentinvolved drivers was then cross-tabulated into a series of contingency tables, each of which were analyzed in order to address empirically the following questions:

(1) Is the relative frequency of accidents involving speeding and drinking in combination greater than that which one would expect based on the random association of accidents involving drinking, speeding, or neither? In other words, is there a speeding-by-drinking interaction?

(2) Is the speeding-by-drinking interaction different for culpable drivers?

(3) Is the speeding-by-drinking interaction different for young drivers and old drivers?

(4) Is the speeding-by-drinking interaction different for inexperienced drivers and experienced drivers?

Sampling Plan

The sampling of accident-involved drivers for analysis was accomplished in two major stages: total sample selection, and selection of analytical subsamples. An outline of the first stage is presented in Figure 1. A restricted random sample of accidents was drawn from the total reported accident population with a sampling fraction of .049 . Non-reportable accidents (no injury and less than $\$ 200$ damage), as well as accidents involving commercial vehicles (large trucks, buses, etc.) or which occurred entirely on schoolyards or playgrounds were excluded from this sample. Accidents which involved drivers who did not reside in North Carolina or who were under 16 years of age were also excluded since no driving experience information was available for these drivers. Each of the 4,311 accidents sampled was scanned to determine the number of vehicles and drivers involved; the accident sample was then converted to a driver sample by taking up to two drivers from each accident (information on the third, and succeeding involved drivers is not contained in the automated file), resulting in a sample of 7,395 accident-involved drivers. After excluding drivers on whom data was missing from the file, a final sample of 7,354 accident-involved drivers was obtained.

Six groups of accident-involved drivers were defined from the final sample as depicted in Figure 2. These groups, designated as the basic groups, were: 


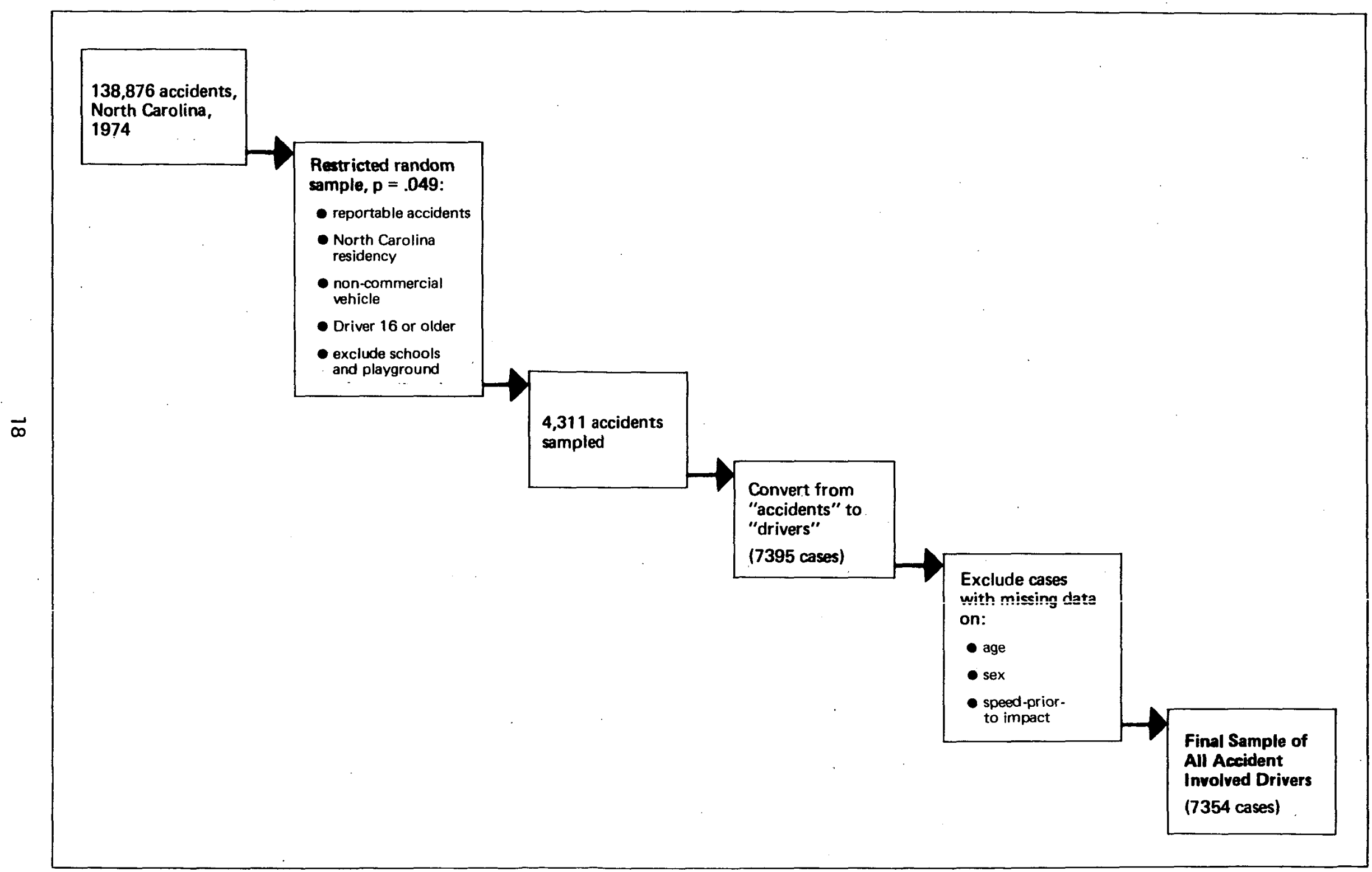

Figure 1. Procedure for selecting the sample 


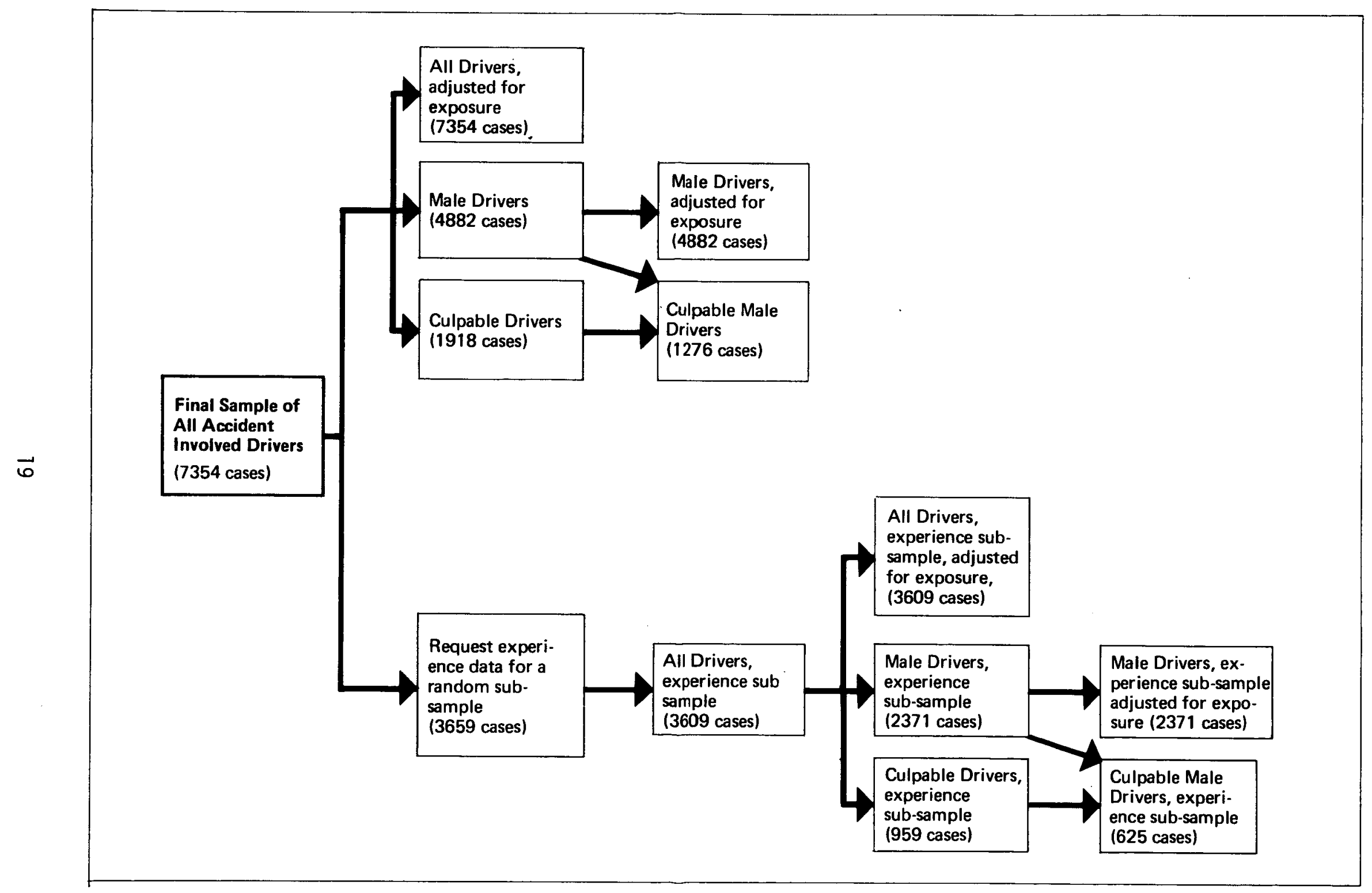

Figure 2. Generation of analytical subsamples 
All accident-involved drivers;

All accident-involved drivers adjusted for exposure-to-risk ${ }^{4}$;

Male accident-involved drivers;

Male accident-involved drivers adjusted for exposure-to-risk;

Culpable drivers; and

Culpable male drivers.

Adjustment for exposure-to-risk was accomplished since earlier studies have indicated that the kinds and amounts of driving done by youthful drivers is different from that of older drivers, and may impact upon accident characteristics (c.f. Pelz and Schuman, 1971). Male drivers were singled out since earlier work suggests that alcohol and speed effects are stronger for male drivers than for females (Preusser et al. 1975). Culpable drivers were examined separately to try to clisentangle alcohol effects which lead to accident-causative driving errors from those which impede accident-avoidance behavior.

Culpable drivers were selected in the following way: If, in a two-vehicle accident, one driver was cited by police for an accidentrelated violation, and the other driver was not cited, then the cited driver was labelled culpable. This conservative definition was employed since all relevant information could be automatically processed. The use of police narratives, a commonly employed procedure, would have been prohibitively expensive.

In addition to these six basic samples, six corresponding samples were derived for the analys is of driving experience (see Figure 2). A random subsample of the full sample of all accident-involved drivers was drawn, and driving record abs tracts for these drivers were requested from the Division of Motor Vehicles. The abstracts were then used to determine the amount of driving experience each driver had prior to his accident. An unambiguous determination of more or less than one year of experience (computed from the date of issue of the driver's original operator license) was made for $98.6 \%$ of the requested abstracts.

${ }^{4}$ The method of induced exposure (Waller, Reinfurt, Freeman, and Imrey, 1973) was used to estimate risk-adjusted frequencies as a function of age and experience. Contingency table entries were then estimated to fit the adjusted age and experience marginals. More traditional, roadside survey exposure data were also obtained and compared to the induced exposure measures using a Chi-square goodness-of-fit test. No significant difference was found between the two estimates $\left(\chi^{2}{ }_{(6)}=5.36, p>.25\right)$. 
The sampling and subsampling procedures resulted in a final set of six basic groups of accident-involved drivers and an additional six groups each representing a corresponding subset of drivers for whom experience data was obtained. These twelve groups constituted the complete data set to be analyzed.

\section{Independent Variables}

Each sampled driver was coded according to the levels of five independent variables. These were age, alcohol involvement, speed involvement, speed prior to impact, and experience. Four categories of age at the time of the accident were used: $16-19,20-24,25-49$, and 50 years old and above. The division at 25 years was selected since it has been the traditional breakpoint between young and old drivers; the other two breakpoints were selected since they have been found empirically to be points of inflection in the alcohol-risk curves in several previous studies (e.g., Borkenstein, Crowther, Schumate, Ziel, and Zylman, 1964), and to provide a more detailed understanding of age effects. Sobriety was coded as either "had been drinking" or "had not been drinking," based on the judgment of the accident investigator. Investigator judgments of "unknown" were included in the "had not been drinking" group. Suspected speeding violations were coded from the judgment of the accident investigator. Estimated speed-priorto-impact was divided into four categories which correspond roughly to four kinds of driving: not moving (standing, waiting, etc.); 1-24 mph (starting, stopping, parking); 25-45 mph (urban driving); and $46 \mathrm{mph}$ and above (highway driving). Drivers for whom driving experience information was available were divided into those with less than one year of experience, and those with more than one year of experience. One year was selected since the acquisition of driving skill is presumed to proceed substantialiy over at least this time span, and it was the longest period which could be reliably determined from the North Carolina records.

\section{Design and Analysis}

Four contingency table designs were used to analyze the data. Two of these contingency tables were associated with the six basic groups. A cross-tabulation based on age by sobriety by speeding violation and one based on age by sobriety by speed-prior-to-impact was used to study the speeding-drinking interactions, and to examine the possible effect of age on these interactions. The other two contingency tables were associated with the corresponding six "experience" groups. Crosstabulations of experience by sobriety by speeding violation, and experience by sobriety by speed-prior-to-impact were used to study the speeding-drinking interaction as a function of the amount of prior driving experience. 
The resulting contingency tables were analyzed using the nonhierarchial log-linear model on each sample and subsample (Goodman, 1970; Shaffer, 1972, 1973). This technique, al though not yet well known, is the only way of obtaining a complete orthogonal decomposition of all simple and higher-order interaction effects for multi-dimensional contingency tables. Some earlier workers have used the analys is of variance in this situation, but, in addition to requiring several unlikely assumptions, the analys is of variance approach uses the highest order interaction effect as an error term (by assuming that it is zero) when analyzing contingency tables. This is clearly unsuitable in the present study, since the highest order interaction effects are of particular interest: they are, in fact, the age-by-speed-by-drinking and experienceby-speed-by-drinking effects. Other studies have used the classical chi-square technique to analyze contingency tables, partitioning the total chi-square to estimate the size of effects due to simple and higher-order interactions. However, Goodman (1964) has demonstrated that this method is incorrect. 


\section{RESULTS AND DISCUSSION}

A contingency table corresponding to each of the four design models was derived for each of the 12 groups studied. Log-linear analyses were performed on the data in each contingency table. An examination of these analyses revealed that the six basic groups clustered into two sets with essentially identical results. The first set consisted of the four groups, all drivers, all drivers adjusted for exposure, male drivers, and male drivers adjusted for exposure; the second set included the culpable and culpable male groups.

The only major difference among groups in the first set was between adjusted and non-adjusted groups. Adjustment for exposure decreased the size of the age and experience ma in effects, and, to a small extent, increased the size of other effects not involving age. These changes are to be expected, and represent a reduction in uncontrolled variability in the unadjusted data resulting from removal of the age-exposure confounding. It was also expected that the male driver group would show stronger alcohol effects than the group including all drivers but this increase was, in fact, very small.

Since these two sets of groups represent two fairly homogeneous patterns of findings, the results will be presented with reference to one group from each set, all accident-involved drivers, and culpable drivers. Results will also be presented for the two corresponding groups on which experience data was obtained. Thus, the description of findings to follow will consider a total of four of the 12 groups studied; all drivers, a subsample of all drivers for whom experience data was obtained, culpable drivers, and a subsample of culpable drivers for whom experience data was obtained. Tables 6 and 7 present the contingency tables for these four groups of drivers. Similar tables for the remaining groups are presented in Appendix $A$ but will not be discussed further. The log-linear analys is summary tables for these four groups are presented in Tables 8 and 9; summary tables for the remaining groups are presented in Appendix B.

The results are presented in two parts. This section deals with the outcomes of analyses as they relate to the four major questions of the study. Appendix E briefly presents a set of auxiliary findings available from the complete log-linear analysis.

Each of the four major questions which were the basis of this study was addressed by considering one or more interaction effects. The relevant results are presented below.

Is there a speeding-by-drinking interaction? The analys is of all accident-involved drivers indicated that there was a statistically significant interaction between drinking and speeding violations (see Table 8). Table 10a shows the proportions of drivers expected to be speeding and drinking, speeding but not drinking, drinking but not speeding, and neither 
Table 6

Driver Frequency Contingency Table for A11 Accident-[nvolved Drivers

a) Suspected Speeding Violation

\begin{tabular}{lrr|rr}
\multicolumn{2}{c}{ Speeding Violation } & \multicolumn{2}{c|}{ Sober } & \multicolumn{2}{c}{ Drinking } \\
Age & & No & & No \\
$16-19$ & 1194 & 251 & 44 & 43 \\
$20-24$ & 1160 & 133 & 78 & 59 \\
$25-49$ & 2539 & 207 & 204 & 80 \\
$50+$ & 1238 & 61 & 54 & 9 \\
\hline
\end{tabular}

b) Speed-Prior-to-Impact

Speed-prior-toimpact (mph)

Age

$$
\text { 16-19 }
$$

20-24

25-49

$50+$

\section{Sober \\ $\begin{array}{llll}0 & 1-24 & 25-45 & 46+\end{array}$}

$\begin{array}{llll}226 & 441 & 547 & 231\end{array}$

$\begin{array}{llll}247 & 414 & 471 & 161\end{array}$

$\begin{array}{llll}577 & 957 & 943 & 269\end{array}$

232
Drinking

$\begin{array}{llll}0 & 1-24 & 25-45 & 46+\end{array}$

c) Suspected Speeding Violation--Experience Subsample

\begin{tabular}{|c|c|c|c|c|c|c|c|c|}
\hline \multirow{2}{*}{ Speeding Violation } & \multicolumn{4}{|c|}{ Sober } & \multicolumn{4}{|c|}{ Drinking } \\
\hline & & No & & Yes & No & & & Yes \\
\hline \multicolumn{9}{|l|}{ Experience } \\
\hline$\leq 1$ year & & 355 & & 55 & 16 & & & 11 \\
\hline$>1$ year & & 646 & & 268 & 181 & & & 77 \\
\hline \multicolumn{9}{|c|}{ d) Speed-Prior-to-Impact--Experience Subsample } \\
\hline & \multicolumn{4}{|c|}{ Sober } & \multicolumn{4}{|c|}{ Drinking } \\
\hline $\begin{array}{l}\text { Speed-prior-to- } \\
\text { impact (mph) }\end{array}$ & 0 & $1-24$ & $25-45$ & $46+$ & 0 & $1-24$ & $25-45$ & $46+$ \\
\hline \multicolumn{9}{|l|}{ Experience } \\
\hline$\leq 1$ year & 73 & 133 & 151 & 53 & 2 & 4 & 8 & 13 \\
\hline$>1$ year & 558 & 1015 & 1032 & 309 & 16 & 34 & 80 & 128 \\
\hline
\end{tabular}


Table 7

Driver Frequency Contingency Table for Culpable Drivers

a) Suspected Speeding Violation

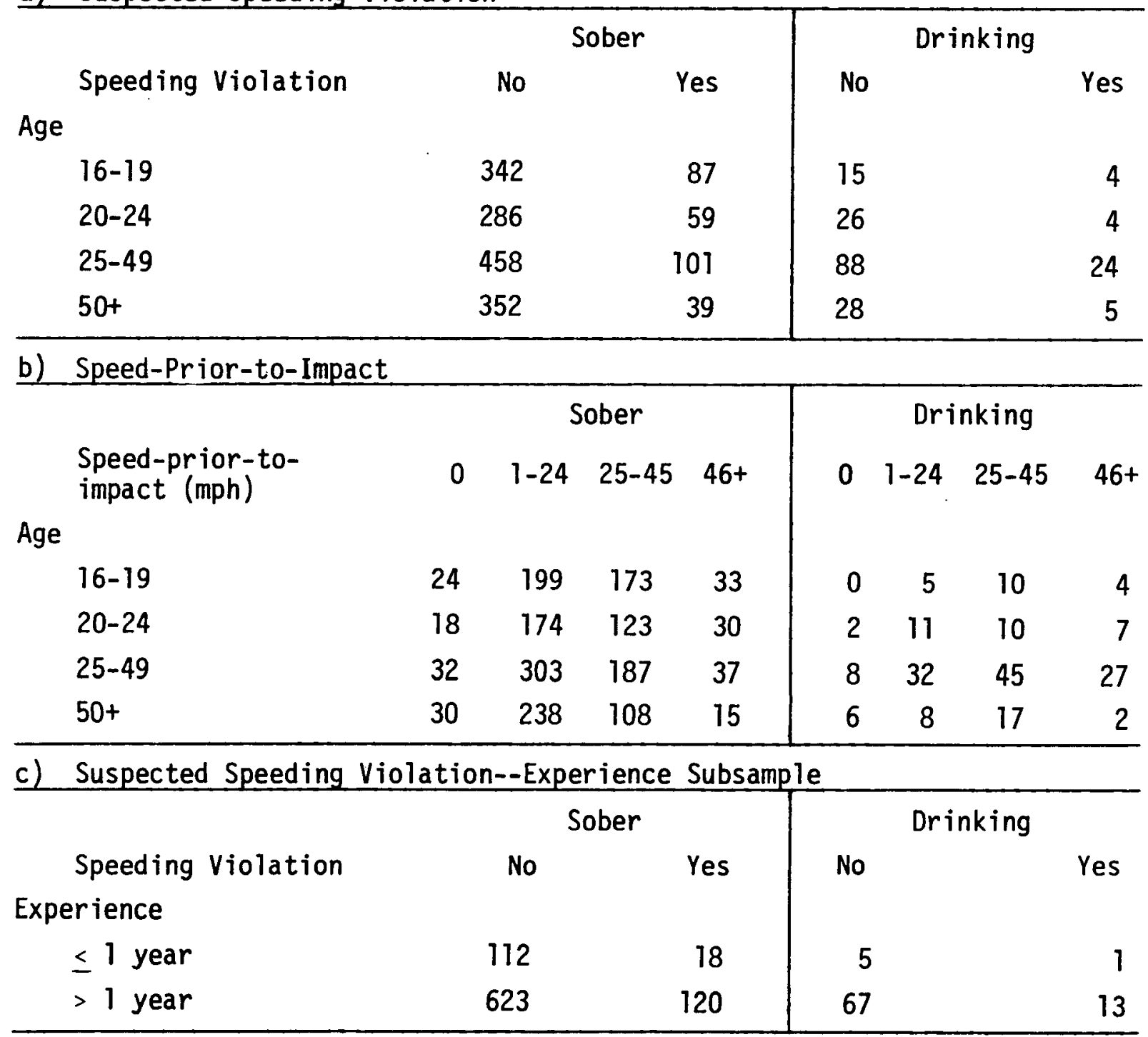

d) Speed-Prior-to-Impact--Experience Subsample

Sober

\begin{tabular}{lllll|llll} 
Speed-prior-to- & 0 & $1-24$ & $25-45$ & $46+$ & 0 & $1-24$ & $25-45$ & $46+$
\end{tabular}

impact (mph)

Experience

$\leq 1$ year

$>1$ year

$\begin{array}{rrrr}5 & 73 & 46 & 6 \\ 48 & 388 & 258 & 49\end{array}$

$\begin{array}{rrrr}1 & 2 & 1 & 2 \\ 7 & 20 & 32 & 21\end{array}$


Table 8

Log-Linear Analys is Summary Table for All Accident-Involved Drivers

a) Suspected Speeding Violation

Degrees of

Freedom

Effect

Age (A)

Speeding Violation (SV)

Drinking (D)

A $\times$ SV

$A \times 0$

D $\times$ SV

$A \times D \times S V$

$D \times S V$ ค $A_{1}$

$D \times S V \in A 2$

$\mathrm{D} \times \mathrm{SV} \mathrm{OA}_{3}$

$D \times S V \in A 4$

Feedom

3

1

3

3

1

3

1

1

1

b) Speed-Prior-to-Impact

Age (A)

Speed (S)

Drink (D)

$A \times S$

$A \times D$

$D \times S$

$A \times D \times S$

$D \times S \in A$

$D \times S \cap A_{2}$

$\mathrm{D} \times \mathrm{S} \mathrm{A}_{3}$

$D \times S \odot A_{4}$
298. $\frac{x^{2}}{59}$

592.76

1150.14

81.87

46.55

155.33

3.46

46.89

93.79

109.75

11.21

273.65

164.72

1583.92

78.70

26.24

227.78

17.55

63.65

122.11

168.89

26.48 $\begin{array}{ll}\frac{p}{.001} & \frac{\phi^{-}}{.20} \\ .001 & .28 \\ .001 & .40\end{array}$

$.001 \quad .11$

$.001 \quad .08$

$.001 \quad .15$

$\mathrm{ns}^{\mathrm{a}} \quad .02$

$.001 \quad .17$

$.001 \quad .26$

$.001 \quad .19$

$\begin{array}{ll}.001 & .09\end{array}$

c) Suspected Speeding Violation--Experience Subsample

Experience (E)

Speeding Violation (SV)

Drinking (D)

$E \times S V$

$E \times D$

$D \times S V$

$E \times D \times S V$

$D \times S V E E_{1}$

$D \times S V \odot E_{2}$
326.06

150.33

384.40

4.44

2.73

45.07

0.02

13.29

91.74

267.16

37.00

467.07

Drink (D)

$E \times S$

$E \times D$

$D \times S$

$E \times D \times S$

$D \times S \in E_{1}$

$D \times S O E_{2}$

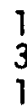

3

1

3

3

3

3
.17$$
\begin{array}{r}
.49 \\
75.50
\end{array}
$$

1.12

16.98

205.49
.001

.001

.001

.001

.001

.001

.05

.001

.001

.001

.001

$a_{\text {Not }}$ significant--p> .05 
Table 9

Log-Linear Analysis Summary Table for Culpable Drivers

\section{a) Suspected Speeding Violation}

Effect

Age (A)

Speeding Violation (SV) Drinking ( 0 )
$A \times S V$
$A \times 0$
$D \times S V$
$A \times D \times S V$
$D \times S V O A_{1}$
$D \times S V \odot A 2$
$\mathrm{D} \times \mathrm{SV} \mathrm{OA}_{3}$
$D \times$ SV O AA

b) Speed-Prior-to-Impact
Degrees of

Freedom

3

1

3

3

1

3

1

1 $\frac{x^{2}}{82.10}$
177.49
387.58

4.64

27.23

0.54

1.22

0.05

0.14

0.78

1.21

\begin{tabular}{|c|c|}
\hline$\underline{p<}$ & $\phi^{\circ}$ \\
\hline $\begin{array}{l}.001 \\
.001 \\
.001\end{array}$ & $\begin{array}{l}.21 \\
.09 \\
.45\end{array}$ \\
\hline $\begin{array}{l}\mathrm{ns}^{\mathrm{a}} \\
.001 \\
\mathrm{~ns}\end{array}$ & $\begin{array}{l}.05 \\
.12 \\
.01\end{array}$ \\
\hline ns & .02 \\
\hline ns & .01 \\
\hline ns & .02 \\
\hline ns & .03 \\
\hline ns & .05 \\
\hline
\end{tabular}

$\frac{\phi^{\circ}}{21}$

.09

.05

.12

.02

.01

.03

.05

Age (A)

Speed (S)

Drink (D)
$A \times S$
$A \times D$
$D \times S$
$A \times D \times S$
$D \times S \& A$
$D \times S \odot A_{2}$
$D \times S \in A_{3}$
$D \times S \in A_{4}$

70.60

161.03

267.26

19.27

26.74

27.97

9.88

5.57

6.41

34.20

15.69

$\begin{array}{ll}.001 & .19 \\ .001 & .29 \\ .001 & .37 \\ .05 & .06 \\ .005 & .12 \\ .001 & .12 \\ \text { ns } & .07 \\ \text { ns } & .11 \\ \text { ns } & .13 \\ .001 & .23 \\ .005 & .19\end{array}$

c) Suspected Speeding Violation--Experience Subsample

Experience (E)

Speeding Violation (SV)

Drinking (D)

\subsection{4}

40.01

97.86

$E \times S V$

$E \times D$

$D \times S V$

$E \times D \times S V$

$D \times S V \in E_{1}$

$D \times S V \odot E_{2}$

$\begin{array}{lll}0.02 & \text { ns } & .00 \\ 1.24 & \text { ns } & .04 \\ 0.29 & \text { ns } & .02 \\ 0.22 & \text { ns } & .02 \\ 0.28 & \text { ns } & .05 \\ 0.01 & \text { ns } & .00\end{array}$

d) Speed-Prior-to-Impact--Experience Subsample

\begin{tabular}{|c|c|c|c|c|}
\hline $\begin{array}{l}\text { Experience (E) } \\
\text { Speed (S) } \\
\text { Drink (D) }\end{array}$ & $\begin{array}{l}1 \\
3 \\
1\end{array}$ & $\begin{array}{r}97.20 \\
37.39 \\
100.24\end{array}$ & $\begin{array}{l}.001 \\
.001 \\
.001\end{array}$ & $\begin{array}{l}.32 \\
.20 \\
.32\end{array}$ \\
\hline $\begin{array}{l}E \times S \\
E \times C \\
D \times\end{array}$ & $\begin{array}{l}3 \\
1 \\
3\end{array}$ & $\begin{array}{r}1.03 \\
0.65 \\
20.81\end{array}$ & $\begin{array}{l}\text { ns } \\
\text { ns } \\
.001\end{array}$ & $\begin{array}{l}.03 \\
.03 \\
.15\end{array}$ \\
\hline$E \times D \times S$ & 3 & 2.59 & ns & .05 \\
\hline $\begin{array}{lllll}D & \times & S & \ddots & E_{1} \\
D & \times & S & \odot & E_{2}\end{array}$ & $\begin{array}{l}3 \\
3\end{array}$ & $\begin{array}{r}8.97 \\
34.70\end{array}$ & $\begin{array}{l}.05 \\
.001\end{array}$ & $\begin{array}{l}.26 \\
.21\end{array}$ \\
\hline
\end{tabular}

${ }^{a}$ Not significant--p> .05 
Table 10

Expected and Obtained Percentages of A11

Accident-Involved Drivers as a

Function of Speeding and Drinking

\begin{tabular}{|c|c|c|c|c|c|}
\hline \multicolumn{3}{|r|}{ A } & & \multicolumn{2}{|c|}{ B } \\
\hline & \multicolumn{2}{|c|}{$\begin{array}{c}\text { Suspected Speeding } \\
\text { Violation }\end{array}$} & & \multicolumn{2}{|c|}{$\begin{array}{c}\text { Suspected Speeding } \\
\text { Violation }\end{array}$} \\
\hline & Yes & No & & Yes & No \\
\hline Drinking & $.9 \%$ & $6.9 \%$ & Drinking & $2.6 \%$ & $5.2 \%$ \\
\hline Sober & $10.6 \%$ & $81.8 \%$ & Sober & $8.9 \%$ & $83.4 \%$ \\
\hline
\end{tabular}


speeding nor drinking under the null hypothesis of independence between speeding and drinking. Table lob shows the proportions of drivers in each of these categories actually found in the sample. If speeding and drinking were independent, the observed and expected proportions in the speeding-drinking cell would be about the same. In fact, it can be seen that the proportion of drivers who are both speeding and drinking is about 2.5 times greater than would be expected for this category. While only $2.6 \%$ of all accident-involved drivers were found to be both speeding and drinking, note that this represents fully one-third of all of the drinking drivers.

The interaction of drinking with speed-prior-to-impact was also examined and found to be significant (see Table 8). This interaction is depicted in Table 11 as differences between observed and expected proportions. It can be seen that the proportion of drinking drivers differed substantially from the proportions expected under the null hypothesis of independence between drinking and speed-prior-to-impact in three of the four speed categories. The proportion of drinking drivers found in each speed category increased as speed-prior-to-impact increased. In the highest speed category 3.5 times as many drinking drivers as would be expected were found. It should also be noted that fully $45 \%$ of all accident-involved drivers who were drinking were traveling above $46 \mathrm{mph}$.

Note that, while both these interactions are statistically quite strong, only 1.5 to $2 \%$ of a 11 accidents examined involved the combination of drinking and speeding, or drinking and high speed-prior-to-impact, respectively. Thus, while the effects are reliable, the implications for countermeasures are unclear. Even if one had a 100\% effective countermeasure for the combination of speeding and drinking, the impact on the entire accident population would be small.

Is the speeding-by-drinking interaction different for culpable drivers? In contrast to the finding for all drivers, the analysis of the speeding violations by drinking interaction for the culpable driver group revealed no significant effect (see Table 9). Culpable drivers were found to be drinking and speeding in about $1.9 \%$ of their accidents, as compared with the $1.7 \%$ expected. The interaction of drinking and speed-prior-toimpact, however, was significant for culpable drivers, although the size of the effect was somewhat smaller than for all drivers. As was the case for all drivers, there were more culpable drivers than were expected in the drinking-and-driving-faster-than-46-mph condition. Two percent of the culpable drivers were observed in this condition, which is about 2.5 times the expected rate.

Is the speeding-by-drinking interaction different for young drivers and older drivers? The answer to this question is no. While the drinkingby-speeding violation interaction for all accident-involved drivers was significant for each of the four age groups studied (see last four lines, part a, Table 8), the failure of the three-way interaction to achieve 


\section{Table 11}

Expected and Obtained Percentages of A11 Accident-Involved Drivers as a Function of Speed-Prior-to-Impact and Drinking

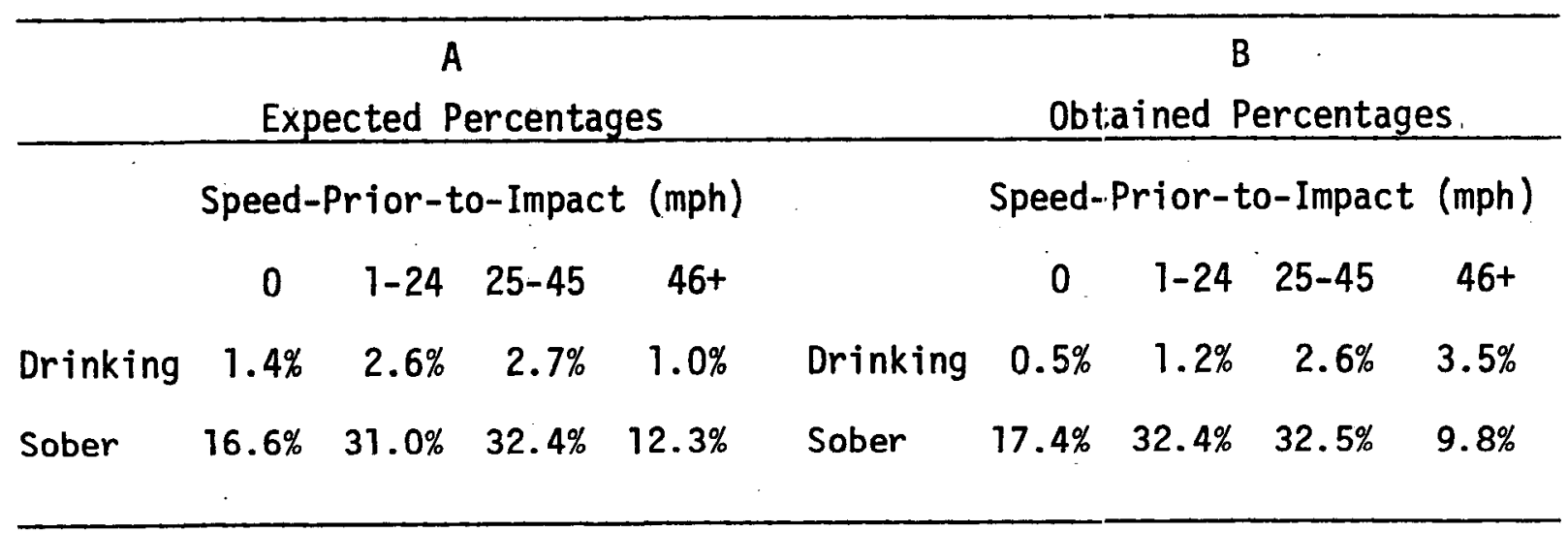


significance indicates that the speeding-drinking relationship did not change as a function of age. Thus, the combination of speeding and drinking had no greater effect on relative accident frequency for young drivers than for old drivers. The interaction of drinking and speeding violations for culpable drivers was not significant for any particular age group, and did not change as a function of age (see last four lines, part a, Table 9).

Examination of Table 8 reveals that a significant effect was found for the interaction of age, speed-prior-to-impact, and drinking (see part $b$ of Table 8). This interaction is depicted in Figure 3 which shows the frequency of driver involvement in accidents (converted to natural logarithms for the sake of clarity) as a function of drinking and speed-priorto-impact within each age category.

The proportion of drinking drivers found in each speed category increased as speed-prior-to-impact increased for the two youngest age groups whereas it increased only up to the 25-45 mph category for the two oldest age groups. A comparison of selected observed and expected proportions revealed that young drivers had more drinking accidents above $46 \mathrm{mph}$ than expected, while older drivers had more drinking accidents than expected in the 25-45 mph range as well as above $46 \mathrm{mph}$. Thus, the older drivers have more drinking accidents than expected over a wider range of speeds than do younger drivers. Therefore, despite the significant age by speed-prior-to-impact by drinking interaction, there is no reason to single out youthful drivers for special treatment in countermeasure development concerned with the combination of drinking and speeding.

Is the speeding-by-drinking interaction different for inexperienced drivers and experienced drivers? No. Neither the experience-by-drinkingby-speeding violation nor the experience-by-drinking-by-speed-prior-toimpact interactions approach significance.

Summary of primary results. The interactions of drinking with speeding violations and with speed-prior-to-impact are statistically significant, but probably too small to be of practical utility for countermeasure design, since the proportion of accident-involved drivers who are found to be both drinking and speeding is very small. These two drinking-by-speeding interactions do not vary as a function of driving experience. The interaction of drinking, speeding violation, and age was not significant. However, when speed was defined in terms of speed-prior-to-impact, the three-way interaction was significant. This did not indicate a consistent relationship between speed and alcohol as a function of age. Rather, it appears as if drinking drivers have an excessive proportion of their accidents in different speed ranges as a function of age: young drinking drivers above $46 \mathrm{mph}$, and older drinking drivers above $25 \mathrm{mph}$.

The strengths of association for each of the relevant interactions are presented in Table 12. 


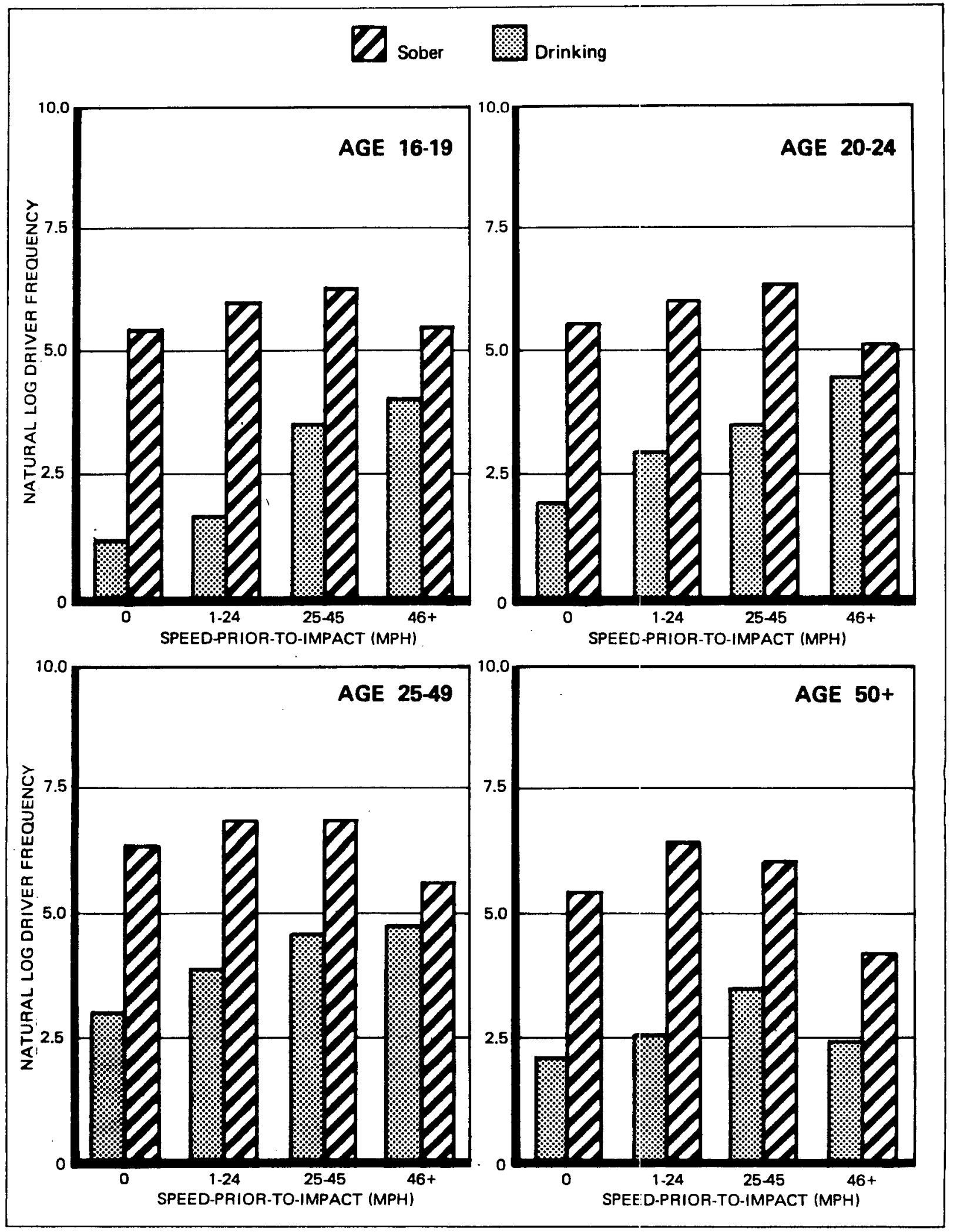

Figure 3. Interaction of speed-prior-to-impact with drinking as a function of age for all accident-involved clrivers. 
Table 12

Summary of Primary Results ${ }^{a}$

\begin{tabular}{|c|c|c|c|c|c|c|}
\hline & $\begin{array}{c}\text { All } \\
\text { Drivers }\end{array}$ & $\begin{array}{c}\text { Al1 Drivers, } \\
\text { Adjusted For } \\
\text { Exposure }\end{array}$ & $\begin{array}{c}\text { Male } \\
\text { Drivers } \\
\end{array}$ & $\begin{array}{c}\text { Male Drivers } \\
\text { Adjusted For } \\
\text { Exposure }\end{array}$ & $\begin{array}{l}\text { Culpable } \\
\text { Drivers }\end{array}$ & $\begin{array}{c}\text { Culpable } \\
\text { Male } \\
\text { Drivers } \\
\end{array}$ \\
\hline \multicolumn{7}{|l|}{$\begin{array}{l}\text { Speeding } \\
\text { Violation: }\end{array}$} \\
\hline $\begin{array}{l}D \times S V(A)_{b}^{b} \\
D \times S V_{(E)}^{b}\end{array}$ & $\begin{array}{l}.15 \\
.11\end{array}$ & $\begin{array}{l}.15 \\
.17\end{array}$ & $\begin{array}{l}.16 \\
.12\end{array}$ & $\begin{array}{l}.16 \\
.17\end{array}$ & $\begin{array}{l}.01 \\
.02\end{array}$ & $\begin{array}{l}.00 \\
.01\end{array}$ \\
\hline $\begin{array}{l}A \times D \times S V \\
E \times D \times S V\end{array}$ & $\begin{array}{l}.02 \\
.00\end{array}$ & $\begin{array}{l}.02 \\
.00\end{array}$ & $\begin{array}{l}.02 \\
.00\end{array}$ & $\begin{array}{l}.03 \\
.00\end{array}$ & $\begin{array}{l}.02 \\
.02\end{array}$ & $\begin{array}{l}.04 \\
.02\end{array}$ \\
\hline $\begin{array}{lllll}D & \times S V & \odot & A_{1} \\
D & \times & S V & 0 & A_{2} \\
D & \times & S V & 0 & A_{3} \\
D & \times & S V & 0 & A_{4}\end{array}$ & $\begin{array}{l}.17 \\
.26 \\
.19 \\
.09\end{array}$ & $\begin{array}{l}.17 \\
.26 \\
.19 \\
.09\end{array}$ & $\begin{array}{l}.18 \\
.27 \\
.21 \\
.10\end{array}$ & $\begin{array}{l}.18 \\
.27 \\
.21 \\
.10\end{array}$ & $\begin{array}{l}.01 \\
.02 \\
.03 \\
.05\end{array}$ & $\begin{array}{l}.04 \\
.02 \\
.03 \\
.06\end{array}$ \\
\hline $\begin{array}{llll}D & S V & @ & E_{1} \\
D & S V & \propto & E_{2}\end{array}$ & $\begin{array}{l}.17 \\
.17\end{array}$ & $\begin{array}{l}.17 \\
.17\end{array}$ & $\begin{array}{l}.18 \\
.18\end{array}$ & $\begin{array}{l}.17 \\
.18\end{array}$ & $\begin{array}{l}.05 \\
.00\end{array}$ & $\begin{array}{l}.04 \\
.00\end{array}$ \\
\hline \multicolumn{7}{|l|}{ Speed: } \\
\hline $\begin{array}{l}D \times S(A) b \\
D \times S(E)\end{array}$ & $\begin{array}{l}.18 \\
.14\end{array}$ & $\begin{array}{l}.19 \\
.22\end{array}$ & $\begin{array}{l}.19 \\
.16\end{array}$ & $\begin{array}{l}.20 \\
.25\end{array}$ & $\begin{array}{l}.12 \\
.15\end{array}$ & $\begin{array}{l}.13 \\
.18\end{array}$ \\
\hline $\begin{array}{l}A \times D \times S \\
E \times D \times S\end{array}$ & $\begin{array}{l}.05 \\
.02\end{array}$ & $\begin{array}{l}.04 \\
.00\end{array}$ & $\begin{array}{l}.05 \\
.02\end{array}$ & $\begin{array}{l}.05 \\
.02\end{array}$ & $\begin{array}{l}.07 \\
.05\end{array}$ & $\begin{array}{l}.09 \\
.08\end{array}$ \\
\hline $\begin{array}{lllll}D & \times & S & 0 & A_{1} \\
D & \times & S & 0 & A_{2} \\
D & \times & S & 0 & A_{3} \\
D & \times & S & 0 & A_{4}\end{array}$ & $\begin{array}{l}.20 \\
.29 \\
.24 \\
.14\end{array}$ & $\begin{array}{l}.20 \\
.29 \\
.24 \\
.14\end{array}$ & $\begin{array}{l}.21 \\
.30 \\
.26 \\
.07\end{array}$ & $\begin{array}{l}.21 \\
.31 \\
.26 \\
.16\end{array}$ & $\begin{array}{l}.11 \\
.13 \\
.23 \\
.19\end{array}$ & $\begin{array}{l}.13 \\
.15 \\
.25 \\
.22\end{array}$ \\
\hline $\begin{array}{lllll}D & \times & S & 0 & E_{1} \\
D & \times & S & 0 & E_{2}\end{array}$ & $\begin{array}{l}.20 \\
.25\end{array}$ & $\begin{array}{l}.20 \\
.25\end{array}$ & $\begin{array}{l}.24 \\
.28\end{array}$ & $\begin{array}{l}.24 \\
.28\end{array}$ & $\begin{array}{l}.26 \\
.21\end{array}$ & $\begin{array}{l}.35 \\
.24\end{array}$ \\
\hline
\end{tabular}

a Cell entries are $\phi^{\prime}$, a standardized measure of the strength of the effect which varies between 0 and 1 (Hays, 1963). Significant values are in italics, non-significant are in block type.

b Two estimates are available for these effects, one from the full sample analyzed for age $(A)$, and the other from the experience subsample (E). 


\section{CONCLUSIONS AND RECOMMENDATIONS}

Based on the log-linear analyses of the data, conclusions and recommendations corresponding to the four primary experimental questions are discussed below.

First, accident-involved drivers who were judged to have been drinking and were suspected of a speeding violation did have a significantly higher accident frequency than expected relative to accident-involved drivers who had been drinking but not speeding, speeding but not drinking, or neither. Further, when speed-prior-to-impact was considered, accident-involved drivers who had been drinking were involved in more accidents than expected at speeds above $46 \mathrm{mph}$. Although both the drinking-by-speeding violation and drinkingby-speed-prior-to-impact interactions were statistically reliable, the critical category of speeding and drinking included a very small proportion of drivers. Thus, it is recommended that a signficant effort not be expended) to develop or implement a special countermeasure targeted precisely at the combination of speeding and drinking at this time, since even a highly effective countermeasure would have a relatively minor impact on the total accident problem. Rather, resources might be better devoted to developing improved countermeasure responses to the problems of speeding and drinking independently. Such an approach is likely to have an impact on the speeding and drinking combination as an incidental benefit. One caveat should be raised regarding this recommendation: it is possible that the small proportion of speeding-drinking accidents includes an inordinate proportion of serious injury or fatality accidents. If this is the case, the low frequency of accidents involving this combination of factors is of less concern relative to the serious consequences of such accidents. The net result may then be a determination that it would be desirable to develop countermeasures specially designed to reduce accidents precipitated by the joint influence of drinking and speeding.

Second, the findings regarding culpable drivers in speeding-drinking accidents appear to be counterintuitive. These drivers, like all accidentinvolved drivers, had an excess of drinking accidents at speeds above $46 \mathrm{mph}$. However, no significant interaction between drinking and speeding violations was found for culpable drivers. Perhaps the methodology for assessing culpability is not adequate. If these findings are substantiated in future research, alternative explanations will have to be explored. In the meantime, the result should be interpreted with caution.

Third, the results of the analyses of the interactions of drinking and speeding violations with age, as well as drinking and speed-prior-to-impact with age indicated that the speeding-drinking problem is not a special problem of young drivers. Therefore it is recommended that, if efforts are launched to impact upon the speeding-drinking combination, no concern should be given to the age of the driver. The significant interaction between age and drinking suggests a potentialiy effective new approach to alcohol countermeasure design targeted at specific age groups. The age-by-drinking-by-speed-priorto-impact interaction provides a clue for developing such countermeasures. 
Speed-prior-to-impact may represent, to a large extent, underlying factors such as type of road, time of day, traffic congestion, and so on. If this is the case, then the interaction may, in fact, be an age-drinking-situation interaction. While this is admittediy speculative, it may be empirically verified using the same approach taken in this project. If this relationship is substantiated, then one may be able to make positive statements about the times, places, and events leading up to frequent kinds of alcohol accidents as a function of age. Alcohol countermeasures aimed at particular age segments of the population might be developed which take advantage of locational or situational differences among the alcohol accidents for different age groups. For example, two prototypes might be:

- young drivers have an excessive number of alcohol accidents after drinking in "singles bars" on weekend evenings and driving home on uncongested, highspeed, roadways,

while

- older drivers have an excessive number of alcohol accidents after drinking in business district bars between 3 and 5 P.M., and driving home on rush-hour congested urban streets.

In such cases, one could develop and promote countermeasures to be especially relevant to these prototypes:

- advertise in singles bars that drivers should reduce speed while driving home;

and

- advertise in business district bars that drivers should increase their following distances on the way home.

Finally, experience was not found to be a potent variable in this study in terms of its joint influence with speeding and drinking upon accident frequency. One explanation is that experience is simply less important than its counterpart, age. Another is that the acquisition of driving skill takes place over a much longer period than one year (the experienced vs. inexperienced driver break used in this study). Indeed, the findings of many studies of motor skills have indicated that such skills continue to improve substantialiy over very extended periods (Irion, 1966). Further research on driving experience should consider this possibility when arbitrarily partitioning drivers into experienced and inexperienced groups. It may be more reasonable to consider drivers with several years of driving experience (e.g., less than three years) as inexperienced. 


\section{REFERENCES}

Baker, J. S. Traffic accident investigator's manual for police. Evanston: The Traffic Institute, Northwestern University, 1963.

Borkenstein, R. F., Crowther, R. F., Schumate, R. P., Zie1, W. B., \& Zylman, R. The role of the drinking driver in traffic accidents. Department of Police Administration, Indiana University, Bloomington, Indiana, 1964.

Carlson, W. L. Alcohol usage of the nighttime driver. Journal of Safety Research, 1972, 4, 12-25.

Filkins, L. D., Clark, C. D., Rosenblatt, C. A., Carlson, W. L., Kerlan, M. W. , \& Manson, H. Alcohol abuse and traffic safety: A study of fatalities, DWI offenders, alcoholism, and court-related treatment approaches. Final Report, June 1970. Highway Safety Research Institute, University of Michigan, Ann Arbor, Michigan.

Goodman, L. A. Simple methods for analyzing three-factor interaction in contingency tables. Journal of the American Statistical Association, 1964, 59, 319-352.

Goodman, L. A. The multivariate analys is of qualitative data: Interactions among multiple classifications. Journal of the American Statistical Association, 1970, 65, 226-256.

Hays, W. L. Statistics. New York: Holt, Rinehart \& Winston, 1963.

Irion, A. L. A brief history of research on the acquisition of skill. In E. A. Bilodeau (Ed.) Acquisition of Skill. New York: Academic Press, 1966.

Levine, J. M., \& Samet, M. Information seeking with multiple sources of conflicting and unreliable information. Human Factors, 1973, 15, 407-419.

Levine, J. M., Samet, M. G., \& Brahlek, R. E. Information seeking with input pacing and multiple decision opportunities. Human Factors, $1974,16,384-394$.

Pelz, 0. C., \& Schuman, S. H. Are young drivers really more dangerous after controlling for exposure and experience? Journal of Safety Research, 1971, $\underline{3}, 68-79$.

Preusser, D. F., Oates, J. F., \& Orban, M. S. Identification of countermeasures for the youth crash problem related to alcohol. Report No. ED-74-12, January 1975. Dunlap and Associates, Inc., Darien, Connecticut. 
Shaffer, J. P. Exact procedures for the analysis of multidimensional contingency tables. Behavior Research Methods and Instrumentation, $1972,4,231-236$.

Shaffer, J. P. Defining and testing hypotheses in multidimensional contingency tables. Psychological Bulletin, 19\%3, 79, 127-141.

Waller, J. A. Factors associated with police evaluat:ion of drinking in fatal highway crashes. Journal of Safety Research, 1971, 3, 35-41.

White, S. B., \& Clayton, C. A. Some effects of alcolol, age of driver, and estimated speed on the likelihood of driver injury. Accident Analys is and Prevention, 1972, $\underline{4}, 59-66$. 
APPENDIX A

Additional Driver Frequency Contingency Tables 
Table A-1

Driver Frequency Contingency Table for All

Accident-Involved Drivers Adjusted for Exposure

a) Suspected Speeding Violation

\begin{tabular}{|c|c|c|c|c|c|c|c|c|}
\hline & & & ober & & & Dri & king & \\
\hline Speeding Violation & & No & & Yes & No & & & Yes \\
\hline Age & & & & & & & & \\
\hline $16-19$ & & 954.6 & & 10.9 & 72.0 & & & 70.4 \\
\hline $20-24$ & & 472.0 & & 58.8 & 99.0 & & & 74.9 \\
\hline $25-49$ & & 155.3 & & 4.2 & 92.8 & & & 36.4 \\
\hline $50+$ & & 502.9 & & 4.1 & 65.6 & & & 10.9 \\
\hline b) Speed-Prior-to-Impa & & & & & & & & \\
\hline & & & ober & & & Dril & king & \\
\hline $\begin{array}{l}\text { Speed-prior-to- } \\
\text { impact (mph) }\end{array}$ & 0 & $1-24$ & $25-45$ & $46+$ & 0 & $1-24$ & $25-45$ & $46+$ \\
\hline Age & & & & & & & & \\
\hline $16-19$ & 370.0 & 721.9 & 895.4 & 378.1 & 4.9 & 8.2 & 49.1 & 80.2 \\
\hline $20-24$ & 313.4 & 525.4 & 597.7 & 204.3 & 8.9 & 24.1 & 36.8 & 104.1 \\
\hline $25-49$ & 262.5 & 435.4 & 429.1 & 122.4 & 9.1 & 22.3 & 46.4 & 51.4 \\
\hline $50+$ & 281.7 & 699.3 & 519.6 & 76.5 & 9.7 & 15.8 & 37.6 & 13.3 \\
\hline c) Suspected Speeding & iolation & n--Expe & rience & Subsamp & le & & & \\
\hline & & & ober & & & Drir & king & \\
\hline Speeding Violation & & No & & Yes & No & & & Yes \\
\hline Experience & & & & & & & & \\
\hline$\leq 1$ year & & 1762.6 & & 273.1 & 79.4 & & & 54.6 \\
\hline$>1$ year & & 1201.3 & & 121.7 & 82.2 & & & 35.0 \\
\hline d) Speed-Prior-to-Impa & --Expel & rience & Subsamp & & & & & \\
\hline & & & ober & & & Drir & iking & \\
\hline $\begin{array}{l}\text { Speed-prior-to- } \\
\text { impact (mph) }\end{array}$ & 0 & $1-24$ & $25-45$ & $46+$ & 0 & $1-24$ & $25-45$ & $46+$ \\
\hline Experience & & & & & & & & \\
\hline$\leq 1$ year & 362.5 & 660.3 & 749.7 & 263.1 & 9.9 & 19.9 & 39.7 & 64.5 \\
\hline$>1$ year & 253.3 & 460.8 & 468.5 & 140.3 & 7.3 & 15.4 & 36.3 & 58.1 \\
\hline
\end{tabular}


Table A-2

Driver Frequency Contingency Table for Male Accident-Involved Drivers

a) Suspected Speeding Violation

\begin{tabular}{lrr|rr}
\multicolumn{2}{l}{ Speeding Violation } & \multicolumn{2}{c|}{ Sober } & \multicolumn{2}{c}{ Drinking } \\
Age & No & Yes & No & Yes \\
$16-19$ & 782 & 212 & 38 & 41 \\
$20-24$ & 722 & 93 & 75 & 54 \\
$25-49$ & 1557 & 136 & 180 & 73 \\
$50+$ & 813 & 48 & 49 & 9 \\
\hline
\end{tabular}

b) Speed-Prior-to-Impact

Speed-prior-toimpact (mph)

\section{Sober}

$0 \quad 1-24 \quad 25-45 \quad 46+$

Age

16-19

20-24

25-49

$50+$
$151 \quad 257 \quad 400 \quad 186$

$\begin{array}{llll}154 & 216 & 319 & 126\end{array}$

$\begin{array}{llll}322 & 553 & 625 & 193\end{array}$

$\begin{array}{llll}152 & 359 & 302 \quad 48\end{array}$
Drinking

$0 \quad 1-24 \quad 25-45 \quad 46+$

$\begin{array}{llll}3 & 5 & 26 & 45\end{array}$

$\begin{array}{llll}7 & 17 & 28 & 77\end{array}$

$\begin{array}{llll}20 & 37 \quad 90 \quad 106\end{array}$

$\begin{array}{llll}8 & 10 & 29 & 11\end{array}$

c) Suspected Speeding Violation--Experience Subsample

\begin{tabular}{lrr|rr}
\hline & \multicolumn{2}{c}{ Sober } & \multicolumn{2}{c}{ Drinking } \\
Speeding Violation & No & Yes & No & Yes \\
Experience & & & & 11 \\
$\leq 1$ year & 210 & 49 & 13 & 72 \\
$>1$ year & 1655 & 197 & 164 & 71 \\
\hline
\end{tabular}

d) Speed-Prior-to-Impact--Experience Subsample

Speed-prior-toimpact (mph)

Experience

$$
\begin{aligned}
& \leq 1 \text { year } \\
& >1 \text { year }
\end{aligned}
$$

Sober

0 1-24 25-45 46+

$\begin{array}{llll}45 & 72 & 104 & 38\end{array}$

$\begin{array}{llll}341 & 586 & 694 & 231\end{array}$

Drinking

0 1-24 25-45 46+

$\begin{array}{llll}2 & 2 & 7 & 13\end{array}$

$\begin{array}{llll}16 & 27 & 73 & 120\end{array}$ 
Table A-3

Driver Frequency Contingency Table for Male Accident-Involved Drivers Adjusted for Exposure

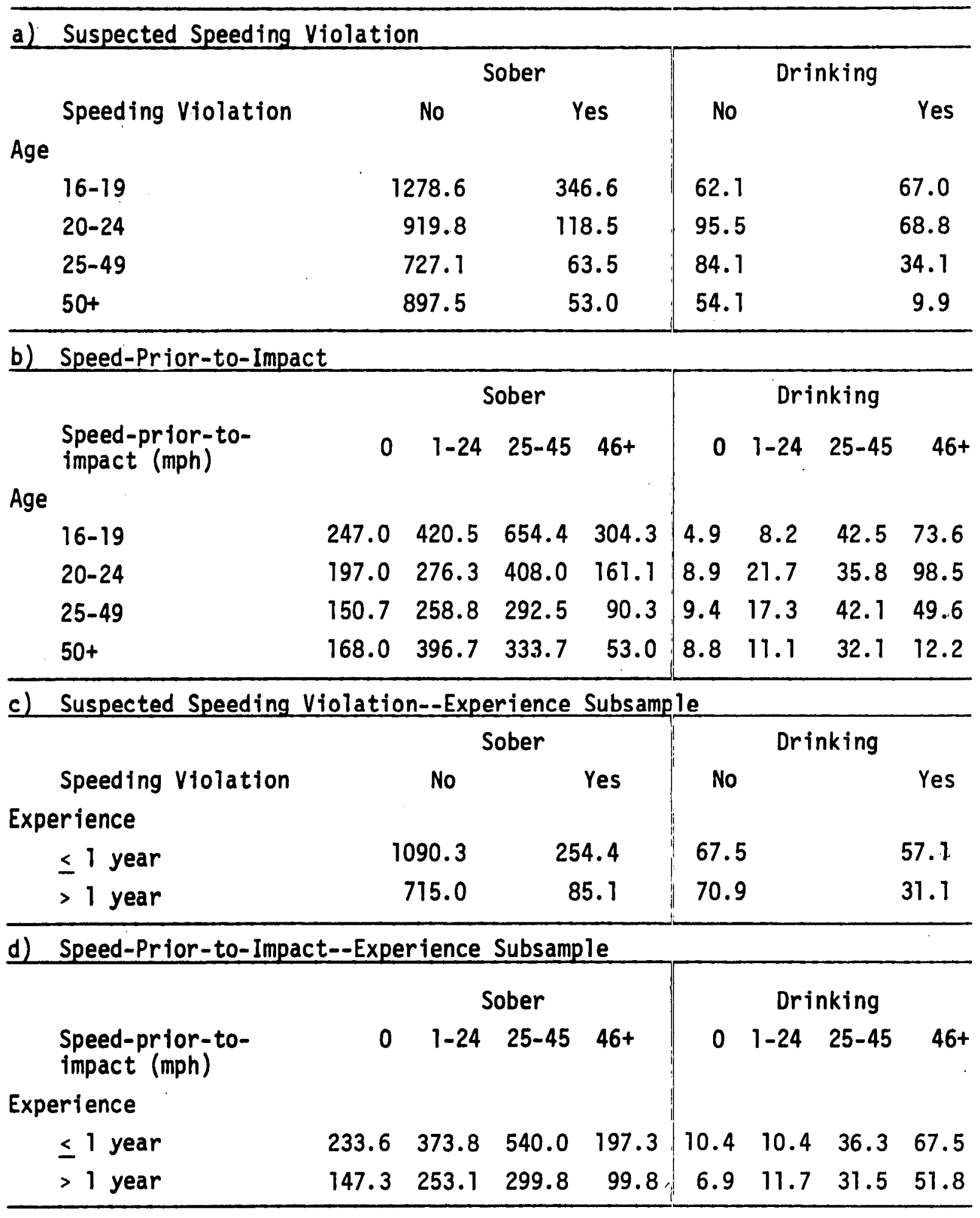


Table A-4

Driver Frequency Contingency Table for Culpable Male Drivers

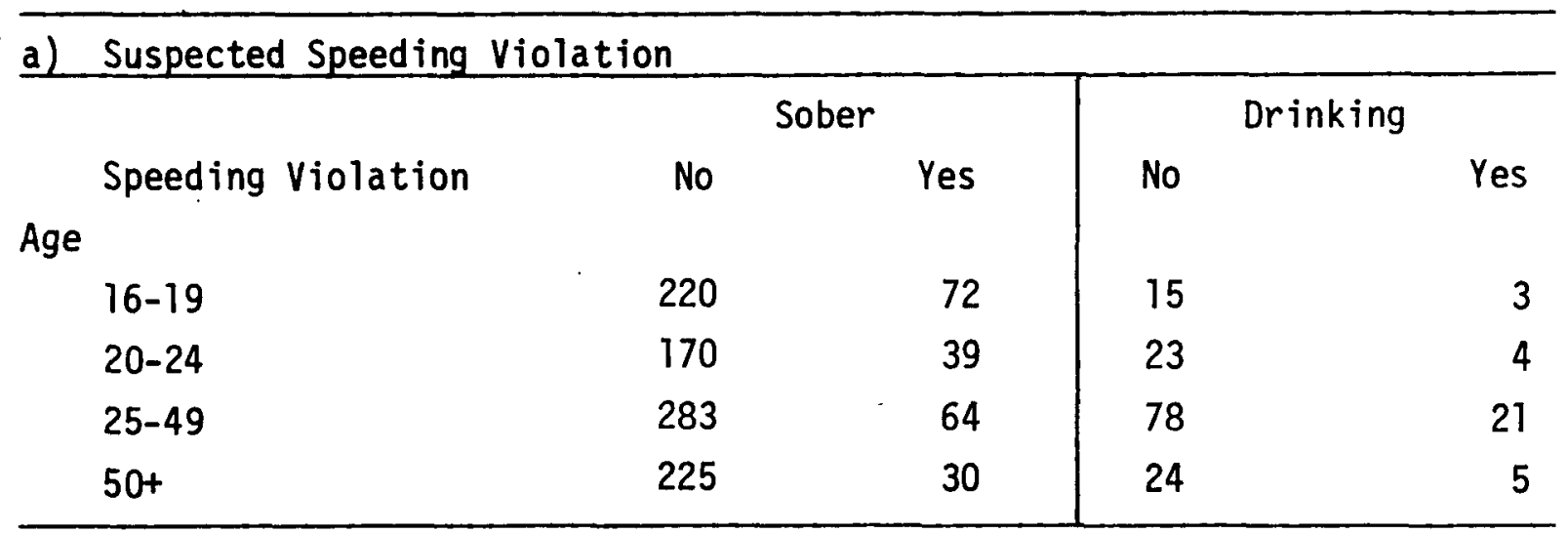

b) Speed-Prior-to-Impact

Speed-prior-to-

impact (mph)

Sober

Drinking Age

$16-19$

20-24

25-49

$50+$

$0 \quad 1-24 \quad 25-45 \quad 46+$

$\begin{array}{llll}0 & 1-24 & 25-45 \quad 46+\end{array}$

$50+$

c) Suspected Speeding Violation--Experience Subsample

\begin{tabular}{|c|c|c|c|c|c|c|c|c|}
\hline \multirow{2}{*}{ Speeding Violation } & \multicolumn{4}{|c|}{ Sober } & \multicolumn{4}{|c|}{ Drinking } \\
\hline & & No & & Yes & No & & & Yes \\
\hline \multicolumn{9}{|l|}{ Experience } \\
\hline$\leq 1$ year & & 69 & & 15 & 4 & & & 1 \\
\hline$>1$ year & & 384 & & 80 & 60 & & & 12 \\
\hline \multicolumn{9}{|c|}{ d) Speed-Prior-to-Impact--Experience Subsample } \\
\hline & \multicolumn{4}{|c|}{ Sober } & \multicolumn{4}{|c|}{ Drinking } \\
\hline $\begin{array}{l}\text { Speed-prior-to- } \\
\text { impact (mph) }\end{array}$ & 0 & $1-24$ & $25-45$ & $46+$ & 0 & $1-24$ & $25-45$ & $46+$ \\
\hline \multicolumn{9}{|l|}{ Experience } \\
\hline$\leq 1$ year & 1 & 43 & 35 & 5 & 1 & 1 & 1 & 2 \\
\hline$>1$ year & 32 & 226 & 176 & 30 & 7 & 17 & 28 & 20 \\
\hline
\end{tabular}




\section{APPENDIX B}

Additional Log-Linear Analysis Summary Tables 
Table B-1

Log-Linear Analysis Summary Table for Al1

Accident-Involved Drivers Adjusted for Expcisure

a) Suspected Speeding Violation

Effect

Age (A)

Speeding Violation (SV)

Drinking (D)

\section{Degrees of}

$A \times$ SV

$A \times D$

$D \times$ SV

$A \times D \times S V$

$D \times S V \odot A_{1}$

$D \times S V O A 2$

$D \times S V P A_{3}$

$D \times S V O A 4$
Freedom

1

3

3

3

3

1

1

1 $\frac{x^{2}}{149.93}$
649.41
1260.24
93.42
56.38
166.22
4.36
76.12
118.43
49.62
12.18

25.67

192.38

1837.08

94.68

30.61

263.34

20.47

104.06

155.33

76.88

31.39

$\begin{array}{lll}\frac{p^{<}}{.001} & & \frac{\phi^{-}}{.14} \\ .001 & & .30 \\ .001 & & .41 \\ .001 & & .11 \\ .001 & & .09 \\ .001 & & .15 \\ \mathrm{~ns}^{\mathrm{a}} & & .02 \\ .001 & & .17 \\ .001 & & .26 \\ .001 & & .19 \\ .001 & & .09\end{array}$

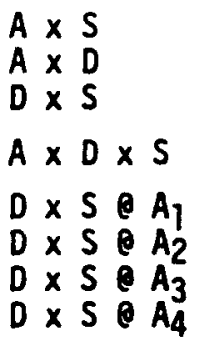

c) Suspected Speeding Violation--Experience Subsample

Experience (E)

Speeding Violation (SV)

Drinking (D)

$E \times S V$

$E \times D$

$D \times S V$

$E \times 0 \times S V$

$D \times S V \cap E_{1}$

$D \times S V \odot E_{2}$
30.21

341.15

878.61

9.63

7.19

100.81

0.03

63.20

41.41

$\begin{array}{ll}.001 & .06 \\ .001 & .16 \\ .001 & .50 \\ .001 & .07 \\ .001 & .06 \\ .001 & .19 \\ .05 & .04 \\ .001 & .20 \\ .001 & .29 \\ .001 & .24 \\ .001 & .14\end{array}$

d) Speed-Prior-to-Impact--Experience Subsample

Experience (E)

Speed (S)

Drink (D)

$E \times S$

$E \times D$

$D \times S$

$E \times D \times S$

$\begin{array}{lllll}D & \times & S & 0 & E_{1} \\ D & \times & S & 0 & E_{2}\end{array}$
14.30

88.51

1028.40

0.27

2.43

178.23

1.50

85.30

93.31
.001

.001

.001

.005

.01

.001

ns

.001

.001 
Table B-2

Log-Linear Analysis Summary Table for Male Accident-Involved Drivers

\begin{tabular}{|c|c|c|c|c|c|}
\hline \multirow[t]{6}{*}{ a) } & \multicolumn{5}{|c|}{ Suspected Speeding Violation } \\
\hline & Effect & $\begin{array}{c}\text { Degrees of } \\
\text { Freedom }\end{array}$ & $\underline{x^{2}}$ & $\underline{\rho}<$ & $\phi^{\prime}$ \\
\hline & $\begin{array}{l}\text { Age (A) } \\
\text { Speeding Violation (SV) } \\
\text { Drinking (D) }\end{array}$ & $\begin{array}{l}3 \\
1 \\
1\end{array}$ & $\begin{array}{l}226.18 \\
474.25 \\
782.55\end{array}$ & $\begin{array}{l}.001 \\
.001 \\
.001\end{array}$ & $\begin{array}{l}.22 \\
.31 \\
.40\end{array}$ \\
\hline & $\begin{array}{l}A \times S V \\
A \times D \\
D \times S V\end{array}$ & $\begin{array}{l}3 \\
3 \\
1\end{array}$ & $\begin{array}{r}78.22 \\
55.36 \\
122.81\end{array}$ & $\begin{array}{l}.001 \\
.001 \\
.001\end{array}$ & $\begin{array}{l}.13 \\
.11 \\
.16\end{array}$ \\
\hline & $A \times D \times S V$ & 3 & 2.45 & $n s^{a}$ & .02 \\
\hline & $\begin{array}{lllll}D & \times & S V & A & A_{1} \\
D & \times & S V & 0 & A_{2} \\
D & \times & S V & 0 & A_{3} \\
D & \times & S V & 0 & A_{4}\end{array}$ & $\begin{array}{l}1 \\
1 \\
1 \\
1\end{array}$ & $\begin{array}{r}33.90 \\
67.64 \\
87.02 \\
9.28\end{array}$ & $\begin{array}{l}.001 \\
.001 \\
.001 \\
.005\end{array}$ & $\begin{array}{l}.18 \\
.27 \\
.21 \\
.10\end{array}$ \\
\hline b) & \multicolumn{5}{|l|}{ Speed-Prior-to-Impact } \\
\hline & $\begin{array}{l}\text { Age (A) } \\
\text { Speed (S) } \\
\text { Drink (D) }\end{array}$ & $\begin{array}{l}3 \\
3 \\
1\end{array}$ & $\begin{array}{r}221.07 \\
151.29 \\
1148.51\end{array}$ & $\begin{array}{l}.001 \\
.001 \\
.001\end{array}$ & $\begin{array}{l}.21 \\
.18 \\
.49\end{array}$ \\
\hline & $\begin{array}{l}A \times S \\
A \times D \\
D \times S\end{array}$ & $\begin{array}{l}9 \\
3 \\
3\end{array}$ & $\begin{array}{r}68.30 \\
28.39 \\
178.72\end{array}$ & $\begin{array}{l}.001 \\
.001 \\
.001\end{array}$ & $\begin{array}{l}.07 \\
.08 \\
.19\end{array}$ \\
\hline & $A \times D \times S$ & 9 & 12.67 & ns & .05 \\
\hline & $\begin{array}{lllll}D & \times & S & P & A_{1} \\
D & \times & S & B & A_{2} \\
D & \times & S & \ddots & A_{3} \\
D & \times & S & \odot & A_{4}\end{array}$ & $\begin{array}{l}3 \\
3 \\
3 \\
3\end{array}$ & $\begin{array}{r}46.58 \\
87.51 \\
129.31 \\
24.10\end{array}$ & $\begin{array}{l}.001 \\
.001 \\
.001 \\
.001\end{array}$ & $\begin{array}{l}.21 \\
.30 \\
.26 \\
.07\end{array}$ \\
\hline \multirow[t]{5}{*}{ c) } & \multicolumn{5}{|c|}{ Suspected Speeding Violation--Experience Subsample } \\
\hline & $\begin{array}{l}\text { Experience (E) } \\
\text { Speeding Violation (SV) } \\
\text { Drinking (D) }\end{array}$ & $\begin{array}{l}1 \\
1 \\
1\end{array}$ & $\begin{array}{r}286.72 \\
98.02 \\
267.17\end{array}$ & $\begin{array}{l}.001 \\
.001 \\
.001\end{array}$ & $\begin{array}{l}.35 \\
.20 \\
.34\end{array}$ \\
\hline & $\begin{array}{l}E \times S V \\
E \times D \\
D \times S V\end{array}$ & $\begin{array}{l}1 \\
1 \\
1\end{array}$ & $\begin{array}{r}8.46 \\
3.79 \\
31.81\end{array}$ & $\begin{array}{l}.005 \\
\mathrm{~ns} \\
.001\end{array}$ & $\begin{array}{l}.06 \\
.04 \\
.12\end{array}$ \\
\hline & $E \times D \times S V$ & 1 & 0.00 & ns & .00 \\
\hline & $\begin{array}{lllll}D & x & S V & E_{1} \\
D & X & S V & \odot & E_{2}\end{array}$ & 1 & $\begin{array}{r}8.91 \\
66.87\end{array}$ & $\begin{array}{l}.005 \\
.001\end{array}$ & $\begin{array}{l}.18 \\
.18\end{array}$ \\
\hline \multirow[t]{5}{*}{ d) } & \multicolumn{5}{|c|}{ Speed-Prior-to-Impact--Experience Subsample } \\
\hline & $\begin{array}{l}\text { Experience (E) } \\
\text { Speed (S) } \\
\text { Drink (D) }\end{array}$ & $\begin{array}{l}1 \\
3 \\
1\end{array}$ & $\begin{array}{r}226.76 \\
35.67 \\
296.95\end{array}$ & $\begin{array}{l}.001 \\
.001 \\
.001\end{array}$ & $\begin{array}{l}.31 \\
.12 \\
.35\end{array}$ \\
\hline & $\begin{array}{l}E \times S \\
E \times D \\
D \times S\end{array}$ & $\begin{array}{l}3 \\
1 \\
3\end{array}$ & $\begin{array}{r}0.76 \\
0.77 \\
62.87\end{array}$ & $\begin{array}{l}\text { ns } \\
\text { ns } \\
.001\end{array}$ & $\begin{array}{l}.02 \\
.02 \\
.16\end{array}$ \\
\hline & $E \times D \times S$ & 3 & 0.62 & ns & .02 \\
\hline & $\begin{array}{lllll}D & \times & S & P & E_{1} \\
D & \times & S & P & E_{2}\end{array}$ & $\begin{array}{l}3 \\
3\end{array}$ & $\begin{array}{r}16.25 \\
159.15\end{array}$ & $\begin{array}{l}.001 \\
.001\end{array}$ & $\begin{array}{l}.24 \\
.28\end{array}$ \\
\hline
\end{tabular}

${ }^{a_{\text {Not }}}$ significant--p> .05 
Table B-3

Log-Linear Analysis Summary Table for

Male Accident-Involved Drivers Adjusted for Exposure

a) Suspected Speeding Violation

Effect

Age (A)

Speeding Violation (SV)

Drinking (D)
A $\times$ SV
$A \times D$
$D \times S V$
$A \times D \times S V$
$D \times S V \cap A_{1}$
$D \times S V \& A 2$
$\mathrm{D} \times \mathrm{SV} \mathrm{OA}_{3}$
$\mathrm{D} \times \mathrm{SV} \cap \mathrm{A4}$

Degrees of

Freedom

3

1

3

3

1

3

1

1

1 $x^{2}$

153.57

493.19

813.78

87.56

66.44

124.59

3.17

54.99

85.73

40.40

9.17 $\frac{p<}{.0}$
.001
.001

.001

.001

.001

.001

$\mathrm{ns}^{\mathrm{a}}$

.001

.001

.001

.005 $\underline{\phi}$

.18

.32

.41

.13

.12

.16

.03

.18

.27

.21

.10

b) Speed-Prior-to-Impact

Age (A)

Speed (S)

Drink (D)

$A \times S$

$A \times D$

$D \times 5$

$A \times D \times S$

$D \times S \in A_{1}$

$D \times S @ A_{2}$

$D \times S \bullet A_{3}$

$\mathrm{D} \times \mathrm{S} \odot \mathrm{A}_{4}$
34.56

172.50

1297.68

79.02

32.72

198.30

14.73

76.72

112.53

60.64

26.17
.001

.001

.001

.001

.001

.001

ns

.001

.001

.001

.001

c) Suspected Speeding Violation--Experience Subsample

Experience (E)

Speeding Violation (SV) Drinking (D)

$E \times S V$

$E \times D$

D $\times$ SV

$E \times D \times S V$

$D \times S V \cap E_{1}$

$D \times S V \odot E_{2}$
44.55

216.90

596.95

18.35

9.54

69.52

0.00

44.62

28.59
.001

.001

.001

.001

.005

.001

ns

.001

.001
.14

.30

.50

.09

.06

.17

.00

.17

.18

d) Speed-Prior-to-Impact--Experience Subsample

Experience (E)

Speed (S)

Drink (D)

$E \times S$

$E \times D$

$D \times 5$

$E \times D \times S$

$D \times S \odot E_{1}$

$D \times S \cap E_{2}$
$1 \quad 14.35$

$3 \quad 85.77$

$1 \quad 687.00$

$3 \quad 2.47$

$1 \quad 3.64$

$3 \quad 151.79$

$3 \quad 0.92$

$3 \quad 86.49$

3

68.77
.001

.001

.001

ns

ns

.001

ns

.001

.001
.08

.19

.54

.03

.04

.25

.02

.24 .28

${ }^{a_{\text {Not }}}$ significant--p> .05 
Table B-4

Log-Linear Analysis Summary Table for Culpable Male Drivers

\section{a) Suspected Speeding Violation}

Effect

Age (A)

Speeding Violation (SV)

Drinking (D)

$\begin{array}{lll}A & \times S V \\ A & \times & D \\ D & \times & S V\end{array}$

Degrees of

$A \times D \times S V$

$D \times S V \odot A_{1}$

$D \times S V \odot A 2$

$\mathrm{D} \times \mathrm{SV} \mathrm{OA}_{3}$

D $\times$ SV $\odot A_{4}$

\section{Freedom}

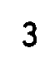

3
1

3

3

1

3

1

1

1

$x^{2}$
63.19
143.28
260.30
2.01
26.74
0.02
1.61
0.38
0.12
0.44
0.99

$\frac{\rho<}{.001}$

.001

.001

$\mathrm{ns}^{\mathrm{a}}$

.001

ns

ns

ns

ns

ns

ns

$\phi$

.22

.34

.45

.04

.14

.00

.04

.04

.02

.03

0.99

.06

b) Speed-Prior-to-Impact

Age $(A)$
Speed $(S)$

Speed (S)
Drink (D)

$A \times S$

$A \times D$

$D \times S$

$A \times D \times S$

$D \times S \cap A_{1}$

$D \times S @ A_{2}$

0
0

$D \times S \cap A_{4}$
56.59

131.12

183.03

16.81

25.76

22.16

10.16

4.86

5.63

27.32

13.66

\section{.001}

.001

.001

ns

.001

.001

ns

ns

ns

.001

.005

c) Suspected Speeding Violation--Experience Subsample

Experience ( $E$ )

Speeding Violation (SV)

Drinking (D)

$E \times S V$

$E \times D$

$D \times S V$

$E \times D \times S V$

$D \times S V \odot E_{1}$

$D \times S V O E_{2}$

60.44

30.52

71.49

.001

.31

1

0.27

1.72

.001

.22

1

0.14

ns

ns

ns

1

0.16

ns

1

0.17

0.00

ns

ns

.01

.02

1

.04

.00

d) Speed-Prior-to-Impact--Experience Subsample

Experience ( $E$

Speed (S)

Drink (D)

\subsection{0}

28.57

50.46

.001

.001

.36

$E \times S$

$E \times D$

$D \times S$

0.56

0.32

21.39

.001

.21

$E \times D \times S$

4.38

ns

$D \times S \in E_{1}$

$D \times S B E_{2}$

10.79

31.21

$.001 \quad .18$

.02

3

3

3

ns

.08

.05

.35

.001

.24

${ }^{a_{N o t}}$ significant--p> .05 
APPENDIX C

North Carolina Accident Report Form 


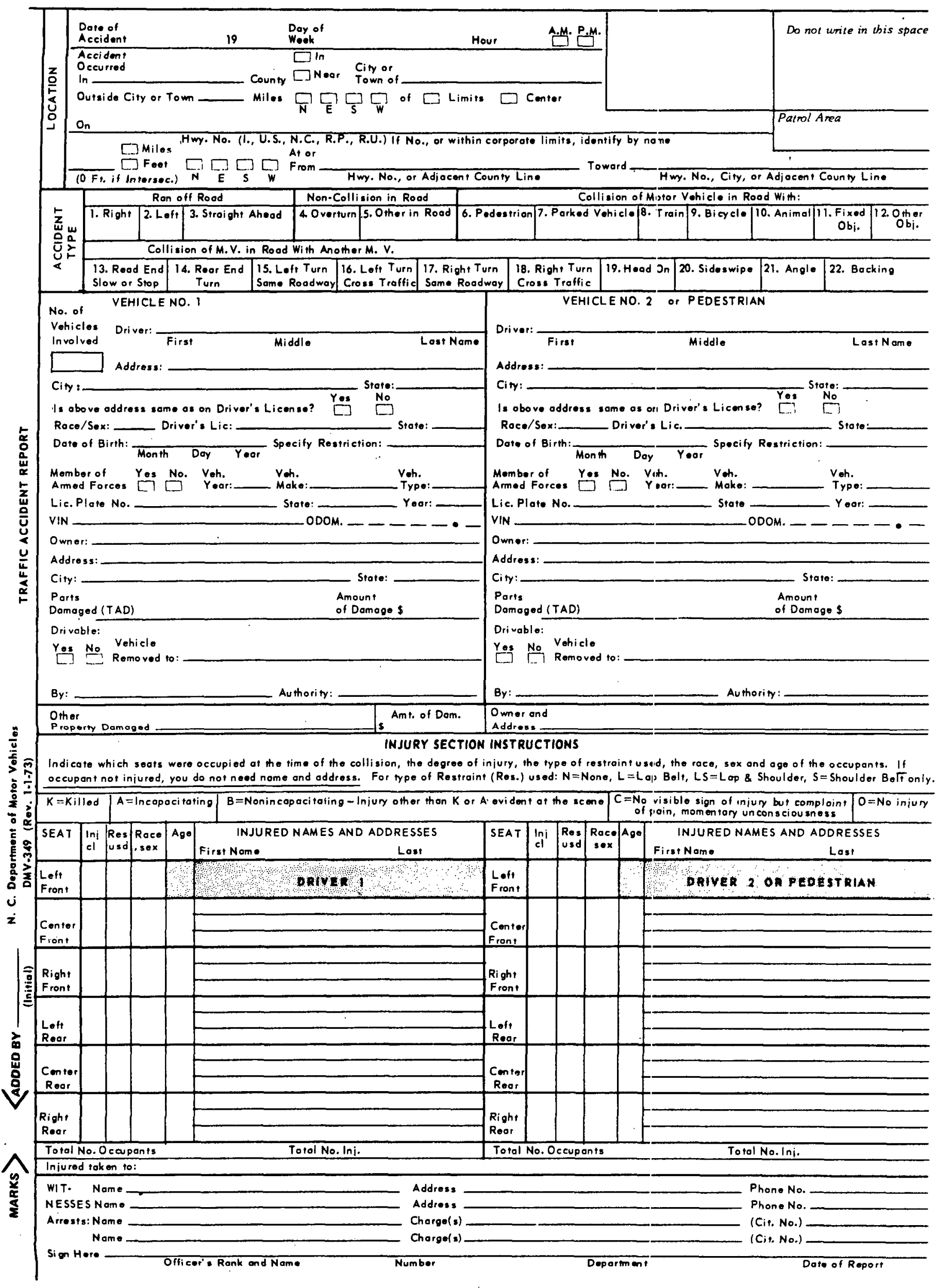




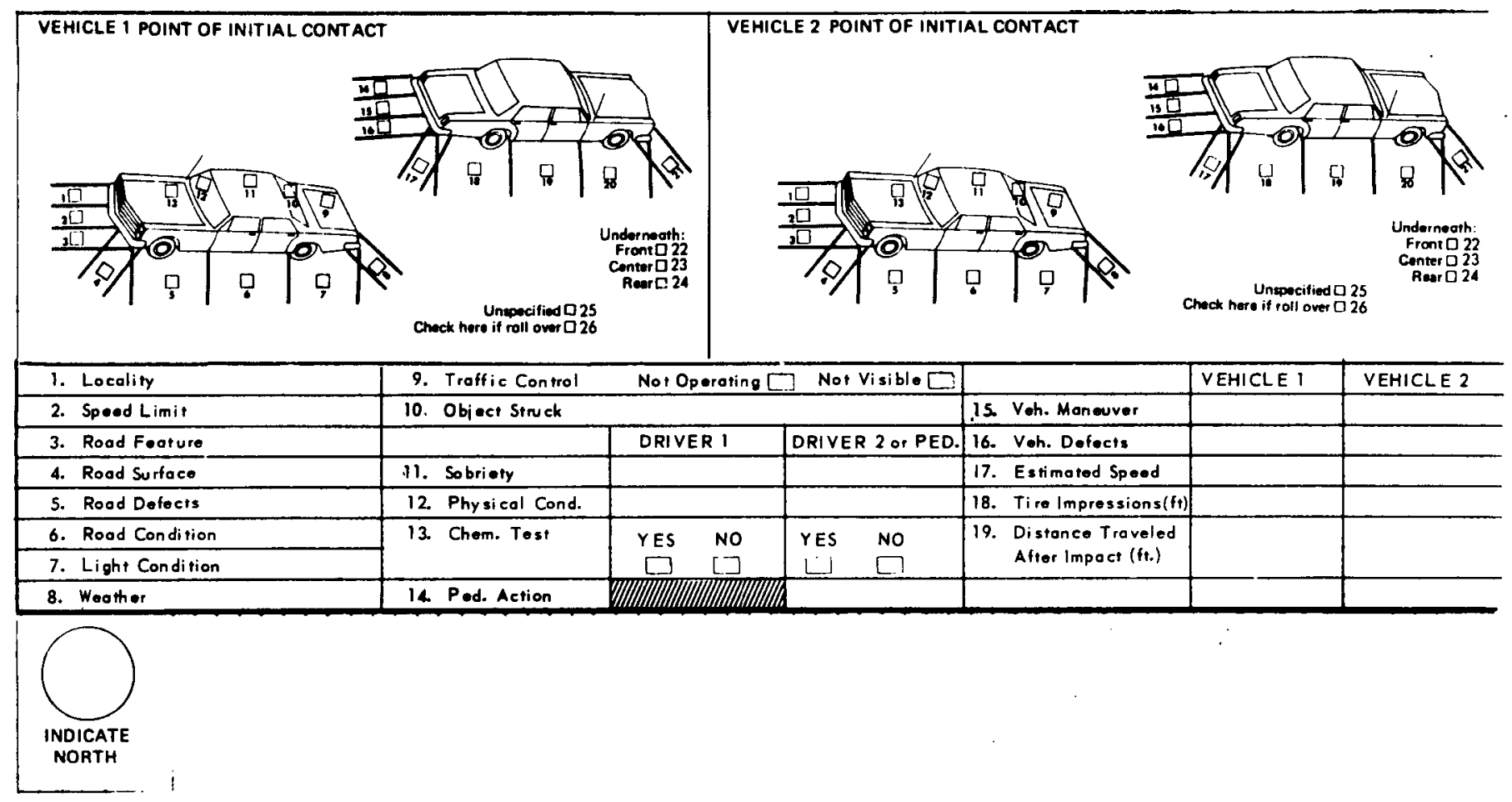

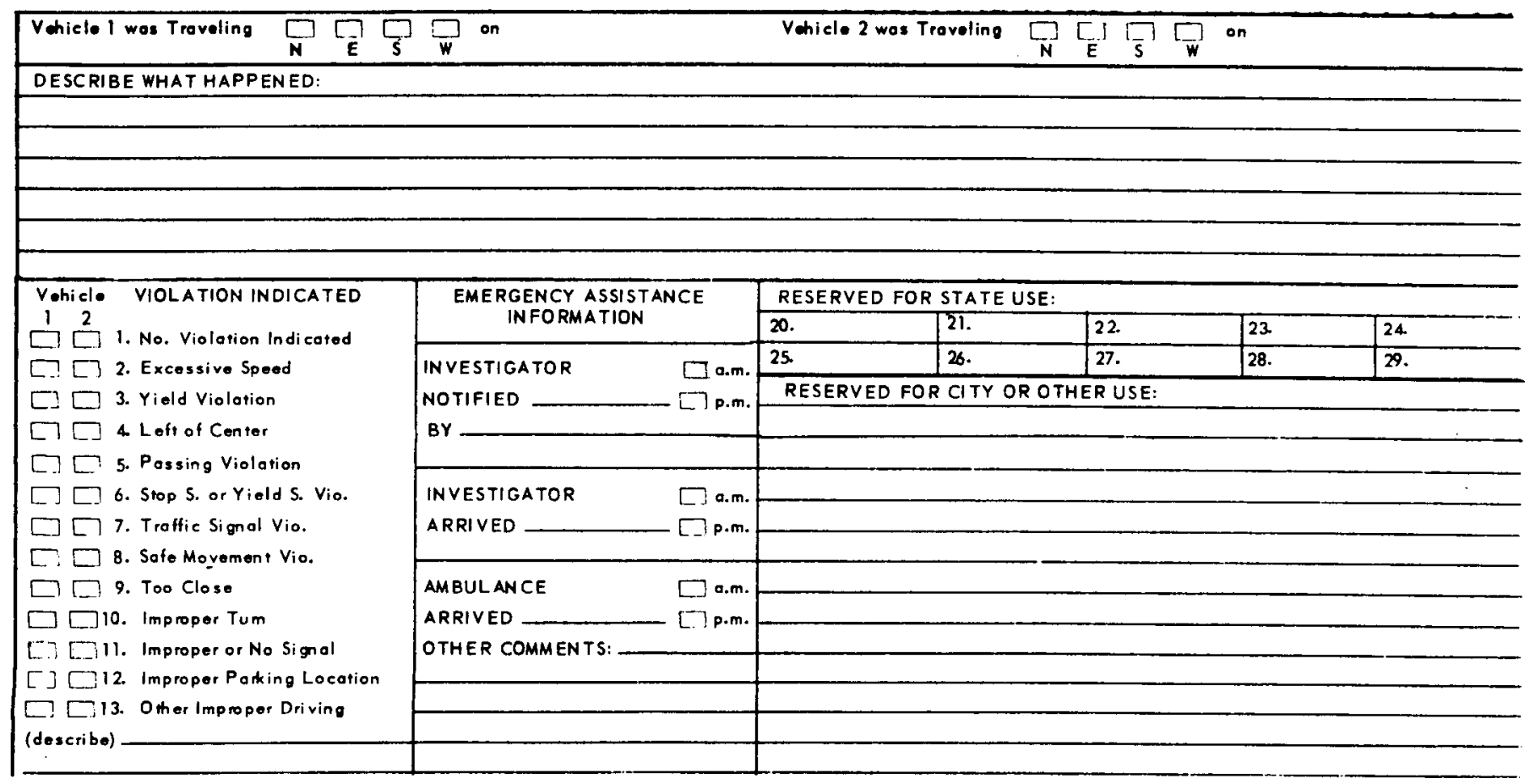




\section{APPENDIX D}

Sample Materials From Data Quality Studies 
This appendix contains samples of the materials used in the field study on data quality. The first four items are the forms used for ranking and rating confidence for the alcohol and speed indicators. The experience questionnaire and a sample scenario booklet follow. 
Chemical Test (Blood, Breath, Urine)

Driver's Appearance

Smell on Driver's Breath

Smell in Driver's Vehicle

Smell in Other Vehicle to Which Driver was Removed

Incriminating Evidence in Vehicle

Driver Admission

Reports from Other Drivers, Passengers, Witnesses

Affective Behavior of Driver at Accident Scene

Driving Behavior of Driver Prior to Accident

Speech Behavior of Driver

Motor Behavior of Driver 
LIST OF INDICATORS WHICH MAY ENABLE POLICE TO JUIJGE THAT A DRIVER IN AN ACCIDENT HAD BEEN DRINKING

\section{Confidence}

Chemical Test (Blood, Breath, Urine)

Driver's Appearance

Smell on Driver's Breath

Sme11 in Driver's Vehicle

Smell in Other Vehicle to Which Driver was Removed

Incriminating Evidence in Vehicle

Driver Admission

Reports from Other Drivers, Passengers, Witnesses

Affective Behavior of Driver at Accident Scene

Driving Behavior of Driver Prior to Accident

Speech Behavior of Driver

Motor Behavior of Driver

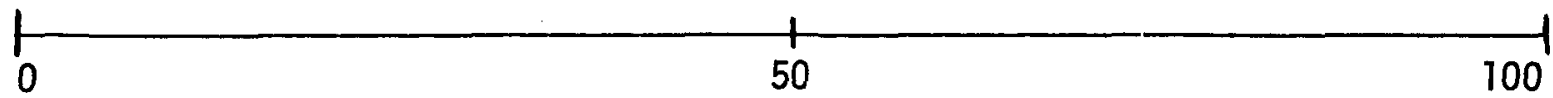




\begin{tabular}{l}
\hline Extent of Damage to Automobile (Interior \& Exterior) \\
Extent of Property Damage \\
Extent of Injuries \\
Driver Reports \\
Passenger Reports \\
Witness Reports \\
Police Observation Prior to Accident \\
Expelled Passenger \\
Path of Vehicle Prior to Impact \\
Path of Vehicle After Impact \\
Skid Marks . \\
Location of Accident Debris
\end{tabular}


LIST OF INDICATORS WHICH MAY ENABLE POLICE TO JUDGE EXCESSIVE SPEED IN AN ACCIDENT

\section{Confidence}

Extent of Damage to Automobile (Interior \& Exterior

Extent of Property Damage

Extent of Injuries

Driver Reports

Passenger Reports

Witness Reports

Police Observation Prior to Accident

Expelled Passenger

Path of Vehicle Prior to Impact

Path of Vehicle After Impact

Skid Marks

Location of Accident Debris

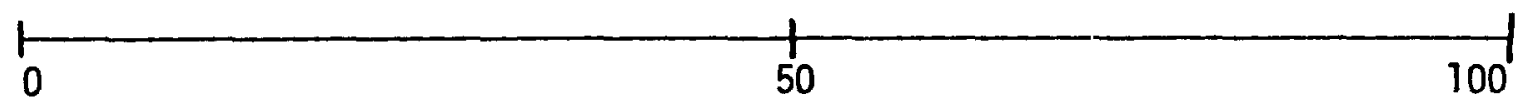


Please complete the following questions concerning your experience.

1. How long have you been in the Highway Patrol?

2. Have you had prior similar experience? If so how long did you serve in each prior position?

3. How old are you?

4. About how many accidents have you investigated within the last month?

5. About how many drinking-driving arrests have you made in the last month?

6. About how many speeding arrests have you made in the last month? 
On the next several pages you will find brief descriptions of several traffic accident situations. Indicate for each accident how you would judge the sobriety of Driver $i$ in the space provided. Use the same codes you normally use on your accident report form:

1. Had not been drinking

2. Drinking--ability impaired

3. Drinking--unable to determine impairment

4. Unknown 
The right front corner of Vehicle 2 impacted on the left rear quarter of Vehicle 1 as Vehicle 2 attempted to pass Vehicle 1 on a divided highway. After the initial collision, Vehicle 2 crossed the grass median strip and collided with the far side guardrail; Vehicle 1 ran off the road to the right, rolled over once, and came to rest against a tree. The 18-year-old driver of Vehicle 1 was killed, but the driver of Vehicle 2 was injured only slightly. He reported that as he overtook Vehicle 1, it was weaving erratically, and crossed over the lane divider while being passed. A broken pint bottle of bourbon is found in the front seat of Vehicle 1, and the smell of alcohol is strong in the vehicle.

$\begin{array}{ll}\text { Sobriety } & \text { Driver } 1 \\ \end{array}$


A 1973 Ford station wagon was hit by a freight train at a rural grade crossing marked with signs but no automatic signal or barrier. The driver of the automobile was a 62-year-old woman, residing in a neighboring state. The engineer reported that the vehicle was stopped on the tracks, and that he applied his brakes and sounded his horn as soon as he saw the vehicle, but was unable to stop in time. The driver apparently was not in the vehicle at the time of impact, and reported that she could remember nothing of the accident. The last thing she recalled was driving down the highway approaching the crossing. The key was in the ignition, but the engine was probably not running at the time of the accident. The engine block was $\mathrm{cool}$ and the emergency brake was on. There was no odor of alcohol detectable on the driver's breath.

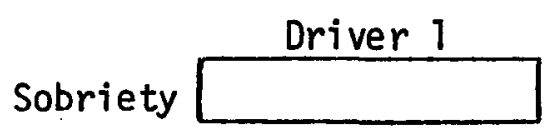


Vehicles 1 and 2 sideswiped each other while avoiding a head-on collision on an access road to an interstate highway at approximately 1 a.m. on a rainy night. The driver of Vehicle 2 accused the driver of Vehicle 1, a slight-looking man of twenty, of having entered the ramp the wrong way. When you arrived on the scene, you called the two parties into your patrol car for questioning. The driver of Vehicle 1 explained that the heavy rain prevented his seeing the "Do Not Enter" sign at the ramp entrance. As the two drivers described what happened, you became aware of a faint smell of alcohol in your vehicle but could not trace it to either driver.

Driver 1

Sobriety 
You come upon the scene of a multiple-car accident in a suburban shopping mall in which one vehicle, traveling erratically and at a high speed, had jumped a parking divider and skidded into a row of parked cars. Witnesses report that the vehicle was used in a robbery of the drive-in bank immediately preceding the accident. The bank teller reports that the driver, a middle-aged male, looked extremely nervous while committing the robbery. The driver, who was seriously injured in the accident, has been taken to the hospital. An examination of the vehicle reveals evidence of the robbery and a half-empty pint bottle of whiskey.

Driver 1

Sobriety 
Vehicle 1 collided with Vehicle 2 at 2 a.m. Vehicle 2 had run out of gas and was abandoned by its driver on the edge of the traffic lane on a well-lighted suburban street. The driver of Vehicle 1 is a middleaged male and he is a local resident. He claims that the headlights of a third vehicle coming in the opposite direction had momentarily blinded him. You note two unopened six-packs of beer on the front seat of his vehicle. His speech is slightly slurred, but his motor movements seem well coordinated. Physical evidence indicates a low-speed collision.

\section{Driver 1}

Sobriety 
You come upon the scene of a single-car accident in which the vehicle failed to negotiate a moderate right-hand curve, ran off the road, and rolled over. Skidmarks indicate the driver applied his brakes as he entered the curve and lost control. The driver is 19 and has no visible injuries. The gas tank of his vehicle has ruptured, and as you lead him away, the wreck bursts into flames. As you attempt to interview him, his speech is slurred and barely coherent. He is unsure of whalt has happened, and suddenly passes out. There is no obvious odor of alcohol on his breath. A witness suggests that he was traveling at a high rate of speed, and this is confirmed by the skidmarks and location of accident debris.

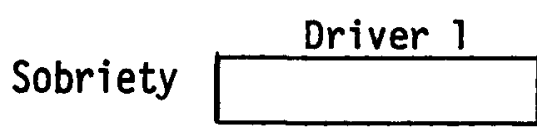


Vehicle 2 collided with Vehicle 1 which had abruptly pulled out of a parking lane in an urban shopping area around 4 p.m. The driver of Vehicle 1, a young white male, jumped out of his car to assess the damage and began to yell obscenities at the driver of Vehicle 2. You arrived at the accident scene in time to witness this outburst. One witness to the accident reported that he thinks he saw the driver of Vehicle 1 leave the tavern up the street ten minutes or so earlier.

Driver 1

Sobriety 
While driving along a rural two-lane road, the driver of Vehicle 2 observed Vehicle 1 ahead of him preparing to make a left-hand turn. (Both drivers agreed that Vehicle l's left turn signal was flashing.) Vehicle 2 pulled onto the shoulder in order to pass Vehicle 1, when Vehicle 1 unexpectedly made a right turn, causing Vehicle 2 to impact on the right side of Vehicle 1. The driver of Vehicle 1 was a well-dressed black male in his fifties and admitted that he wasn't paying as close attention to his driving as he probably should have. He was quite disturbed by the incident; no physical injury was noticed.

$$
\text { Driver } 1
$$

Sobriety 
Vehicle 1 hit the back of Vehicle 2 at 1:30 p.m. while proceeding through the commerical area of town in the right-hand lane. The driver of Vehicle 1 was a 19-year-old white female who was transporting four colleagues from work back to the office after an office party. The woman claims that the driver of Vehicle 2 gave no indication of stopping. The brake lights of Vehicle 2 were both damaged and not operable after the accident. The driver of Vehicle 2, a taxi driver in his forties, stated that traffic was moving at approximately $25 \mathrm{mph}$ and that he stopped to pick up a passenger hailing him from the sidewalk. There were no skidmarks visible from either Vehicle 1 or 2.

Driver 1

Sobriety 
The front of Vehicle 1 hit the side of Vehicle ? in the center of an intersection which has "STOP" signs controlling all four directions. Vehicle 1 was driven by a 38-year-old male, and entered the intersection from the south; Vehicle 2 was driven by an elderly woman and entered the intersection from the east. Both drivers claimed that they had stopped before entering the intersection, and that the other driver had failed to stop. Driver 2 was uninjured but quite anxious and was obviously hard of hearing. Driver 1 was argumentative and threatening. He admitted to having a "couple of beers" at a nearby bar within the last hour.

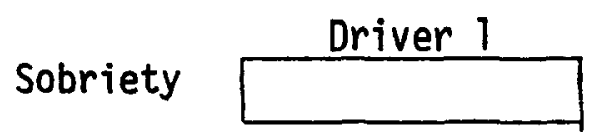


APPENDIX E

Auxiliary Results 


\section{APPENDIX E}

\section{Auxiliary Results}

Because the log-linear analysis provides an orthogonal decomposition of all interactions in a manner analogous to classical analys is of variance, significance tests were performed on several two-way interactions, some of which have been previously investigated and which may be of interest to researchers studying the impact of alcohol and speed on accidents. These findings are presented below.

Age and drinking. The interaction of age and drinking was found to be significant in each of the samples analyzed, and the strength of the association was approximately constant. Generally, the interaction was due to an overinvolvement of 20- to 24-year-olds and 25- to 49-year-olds among the drinking drivers. The 20- to 24-year group was found to be drinking at about 1.25 times the expected frequency, and the 25- to 49year group was found above expectation by only a little less. However, among the culpable and culpable male samples, only the 25- to 49-yearolds were overrepresented among drinking, accident-irivolved drivers; they were found to be drinking at about 1.67 times the expected rate.

Age and speeding violations. Significant age-by-speeding interactions were obtained for all accident-involved drivers and male accident-involved drivers (both raw and adjusted for exposure), but not: for the culpable or culpable male drivers. For the non-culpable samples: this interaction was produced by a higher than expected frequency of speeding violations among accident-involved drivers less than 24 years old. The youngest drivers (16-19) were found to be speeding about $70 \%$ more often than expected, while the 20 - to 24-year-olds were speeding about $15 \%$ more often than expected.

Age and speed-prior-to-impact. The age-by-speed interaction was significant for all samples analyzed. It was characterized by strong overrepresentation of young drivers (16-24) in accidents which involved speeds higher than $46 \mathrm{mph}$, small overinvolvements of drivers 24-49 at speeds of $0 \mathrm{mph}$ and above $46 \mathrm{mph}$, and a large overinvolvement of the oldest drivers ( 50 and older) at speeds between 1 and $24 \mathrm{mph}$.

Experience and drinking. The interaction of drinking and prior driving experience was significant only for the two exposure-adjusted analyses, and in both of these it appeared to be a very weak effect. Note that it was not found that 16- to 19-year-olds (which includes $66 \%$ of our inexperienced drivers) were overinvolved in drinking accidents. The failure to obtain a strong drinking/experience interaction may reflect 
this confounding; since the legal age for drinking in North Carolina is 21 , these findings may not be particularly surprising. 6

Experience and speeding violations. The interaction of experience and speeding, like the interaction of age and speeding, is significant for all groups except the culpable and culpable male groups. This interaction is produced by a higher than expected proportion of inexperienced drivers involved in accidents with speeding violations; they are expected, under the assumption of independence, to be involved and speeding in $1.4 \%$ of the accidents, when, in fact, they are involved in $1.8 \%$ of the accidents.

Experience and speed-prior-to-impact. In none of the analyses were experience significantly associated with speed-prior-to-impact.

${ }^{6}$ The legal age is 21 for all alcoholic beverages except for beer with $3.2 \%$ or less alcohol content. 


\section{APPENDIX $F$ \\ Detailed Crosstabulations}

This appendix presents a detailed breakdown of drinking and speeding violations by sex and by age in years from 16 to 100 . This breakdown is presented for two groups, all accident-drivers and "innocent drivers." The innocent drivers are a subset of all accident drivers selected to be used as the control population for exposure adjustments. The following criterion for selection was used:

For every two-vehicle accident where one driver was charged with an accident-related violation, or suspected of a violation (determined from the violation-indicated section of the report form--see Appendix C) and where the other driver was neither charged nor suspected of a violation, the latter driver was selected for the innocent group. 
Table F-1 (Cont'd)

Detailed Breakdown of Accident-Involved Drivers:

Age by Sobriety by Sex by Speeding Violation

\begin{tabular}{|c|c|c|c|c|c|c|c|c|c|c|c|c|}
\hline \multirow[b]{4}{*}{ Age } & \multicolumn{8}{|c|}{ All Accident-Involved Drivers } & \multicolumn{4}{|c|}{$\begin{array}{c}\text { Innocent } \\
\text { Accident-Involved Drivers }\end{array}$} \\
\hline & \multicolumn{4}{|c|}{ Sober } & \multicolumn{4}{|c|}{ Drinking } & \multirow{2}{*}{\multicolumn{2}{|c|}{ Sober }} & \multirow{2}{*}{\multicolumn{2}{|c|}{ Drinking }} \\
\hline & \multicolumn{2}{|c|}{$\begin{array}{c}\text { No Speeding } \\
\text { Violation } \\
\end{array}$} & \multicolumn{2}{|c|}{$\begin{array}{r}\text { Speeding } \\
\text { Violation } \\
\end{array}$} & \multicolumn{2}{|c|}{$\begin{array}{c}\text { No Speeding } \\
\text { Violation }\end{array}$} & \multicolumn{2}{|c|}{$\begin{array}{l}\text { Speeding } \\
\text { Violation } \\
\end{array}$} & & & & \\
\hline & Male & Fema le & Male & Female & Male & Female & Male & Female & Male & Female & Male & Female \\
\hline 57 & 33 & 16 & 0 & 1 & 2 & 0 & 0 & 0 & 15 & 5 & 0 & 0 \\
\hline 58 & 48 & 27 & 2 & 1 & 3 & 0 & 1 & 0 & 23 & 9 & 0 & 0 \\
\hline 59 & 32 & 18 & 1 & 0 & 3 & 0 & 1 & 0 & 12 & 7 & 0 & 0 \\
\hline 60 & 41 & 16 & 0 & 0 & 1 & 0 & 0 & 0 & 18 & 5 & 0 & 0 \\
\hline 61 & 33 & 15 & 2 & 0 & 4 & 0 & 0 & 0 & 13 & 8 & 0 & 0 \\
\hline 62 & 35 & 13 & 3 & 0 & 1 & 0 & 2 & 0 & 12 & .4 & 0 & 0 \\
\hline 63 & 34 & 18 & 2 & 0 & 1 & 0 & 0 & 0 & 11 & 5 & 0 & 0 \\
\hline 64 & 28 & 19. & 0 & 1 & 0 & 0 & 0 & 0 & 16 & 6 & 0 & 0 \\
\hline 65 & 24 & 10 & 1 & 0 & 1 & 0 & 0 & 0 & 10 & 3 & 0 & 0 \\
\hline 66 & 19 & 15 & 2 & 0 & 0 & 0 & 0 & 0 & 8 & 2 & 0 & 0 \\
\hline 67 & 19 & 13 & 2 & 0 & 1 & 0 & 1 & 0 & 6 & 5 & 0 & 0 \\
\hline 68 & 16 & 11 & 1 & 0 & 0 & 0 & 0 & 0 & 8 & 1 & 0 & 0 \\
\hline 69 & 17 & 9 & 1 & 1 & 0 & 0 & 0 & 0 & 2 & 2 & 0 & 0 \\
\hline 70 & 23 & 6 & 0 & 0 & 1 & 0 & 0 & 0 & 6 & 1 & 0 & 0 \\
\hline 71 & 17 & 11 & 0 & 1 & 0 & 1 & 0 & 0 & 3 & 2 & 0 & 0 \\
\hline 72 & 15 & 3 & 0 & 0 & 0 & 0 & 0 & 0 & 3 & 0 & 0 & 0 \\
\hline 73 & 16 & 6 & 2 & 0 & 1 & 0 & 0 & 0 & 3 & 2 & 0 & 0 \\
\hline 74 & 10 & 7 & 0 & 2 & 0 & 0 & 0 & 0 & 3 & 1 & 0 & 0 \\
\hline 75 & 13 & 4 & 1 & 0 & 0 & 0 & 0 & 0 & 4 & 1 & 0 & 0 \\
\hline 76 & 8 & 1 & 0 & 0 & 0 & 0 & 0 & 0 & 1 & 0 & 0 & 0 \\
\hline 77 & 5 & 0 & $\phi$ & 0 & 0 & 0 & 0 & 0 & 0 & 0 & 0 & 0 \\
\hline 78 & 9 & 2 & 1 & 0 & 0 & 0 & 0 & 0 & 2 & 0 & 0 & 0 \\
\hline 79 & 5 & 1 & 2 & 0 & 0 & 0 & 0 & 0 & 0 & 0 & 0 & 0 \\
\hline 80 & 5 & 1 & 0 & 0 & 0 & 0 & 0 & 0 & 1 & 1 & 0 & 0 \\
\hline 81 & 6 & 0 & 0 & 1 & 0 & 0 & 0 & 0 & 1 & 0 & 0 & 0 \\
\hline 82 & 6 & 1 & 0 & 0 & 0 & 0 & 0 & 0 & 0 & 0 & 0 & 0 \\
\hline 83 & 5 & 1 & 0 & 0 & 0 & 0 & 0 & 0 & 1 & 0. & 0 & 0 \\
\hline 84 & 2 & 0 & 0 & 0 & 0 & 0 & 0 & 0 & 1 & 0 & 0 & 0 \\
\hline 85 & 1 & 1 & 0 & 0 & 0 & 0 & 0 & 0 & 1 & 0 & 0 & 0 \\
\hline 86 & 2 & 1 & 0 & 0 & 0 & 0 & 0 & 0 & 0 & 0 & 0 & 0 \\
\hline 87 & 0 & 0 & 0 & 0 & 0 & 0 & 0 & 0 & 0 & 0 & 0 & 0 \\
\hline 88 & 1 & 0 & 0 & 0 & 0 & 0 & 0 & 0 & 0 & 0 & 0 & 0 \\
\hline 89 & 0 & 1 & 0 & 0 & 0 & 0 & 0 & 0 & 0 & 0 & 0 & 0 \\
\hline 100 & 0 & 0 & 1 & 0 & 0 & 0 & 0 & 0 & 0 & 0 & 0 & 0 \\
\hline
\end{tabular}


Table F-1

Detailed Breakdown of Accident-Involved Drivers:

Age by Sobriety by Sex by Speeding Violation

\begin{tabular}{|c|c|c|c|c|c|c|c|c|c|c|c|c|}
\hline \multirow[b]{4}{*}{ Age } & \multicolumn{8}{|c|}{ All Accident-Involved Orivers } & \multicolumn{4}{|c|}{$\begin{array}{l}\text { Innocent } \\
\text { Accident-Involved Drivers }\end{array}$} \\
\hline & \multicolumn{4}{|c|}{ Sober } & \multicolumn{4}{|c|}{ Drinking } & \multirow{2}{*}{\multicolumn{2}{|c|}{ Sober }} & \multicolumn{2}{|c|}{ Drinking } \\
\hline & \multicolumn{2}{|c|}{$\begin{array}{c}\text { No Speeding } \\
\text { Violation } \\
\end{array}$} & \multicolumn{2}{|c|}{$\begin{array}{r}\text { Speeding } \\
\text { Violation } \\
\end{array}$} & \multicolumn{2}{|c|}{$\begin{array}{c}\text { No Speeding } \\
\text { Violation } \\
\end{array}$} & \multicolumn{2}{|c|}{$\begin{array}{l}\text { Speeding } \\
\text { Violation } \\
\end{array}$} & & & & \\
\hline & Male & Female & Male & Female & Male & Female & Male & Female & Mare & Fema le & Male & Female \\
\hline 16 & 184 & 104 & 52 & 8 & 4 & 0 & 4 & 1 & 46 & 26 & 0 & 0 \\
\hline 17 & 224 & 101 & 66 & 11 & 7 & 1 & 9 & 0 & 61 & 30 & 0 & 0 \\
\hline 18 & 199 & 108 & 54 & 9 & 15 & 2 & 20 & 0 & 55 & 38 & 0 & 0 \\
\hline 19 & 175 & 99 & 40 & 11 & 12 & 3 & 8 & 1 & 50 & 34 & 0 & 1 \\
\hline 20 & 178 & 82 & 21 & 11 & 9 & 0 & 19 & 2 & 59 & 24 & 0 & 0 \\
\hline 21 & 145 & 97 & 25 & 9 & 14 & 2 & 12 & 1 & 51 & 44 & 1 & 0 \\
\hline 22 & 137 & 92 & 20 & 6 & 20 & 0 & 8 & 1 & 59 & 34 & 2 & 0 \\
\hline 23 & 138 & 92 & 20 & 9 & 16 & 0 & 6 & 1 & 51 & 30 & 1 & 0 \\
\hline 24 & 124 & 75 & 7 & 5 & 16 & 1 & 9 & 0 & 47 & 36 & 1 & 0 \\
\hline 25 & 104 & 60 & 15 & 4 & 11 & 0 & 5 & 0 & 51 & 30 & 3 & 0 \\
\hline 26 & 137 & 67 & 16 & 3 & 10 & 3 & 11 & 0 & 70 & 31 & 0 & 0 \\
\hline 27 & 100 & 66 & 14 & 6 & 19 & 1 & 8 & 2 & 35 & 27 & 4 & 1 \\
\hline 28 & 100 & 54 & 15 & 7 & 11 & 2 & 3 & 0 & 44 & 28 & 2 & 0 \\
\hline 29 & 63 & 49 & 8 & 4 & 8 & 1 & 6 & 0 & 28 & 25 & 1 & 1 \\
\hline 30 & 84 & 50 & 3 & 9 & 10 & 1 & 5 & 1 & 39 & 26 & 1 & 0 \\
\hline 31 & 85 & 52 & 6 & 5 & 9 & 2 & 4 & 0 & 36 & 27 & 2 & 1 \\
\hline 32 & 65 & 42 & 6 & 4 & 7 & 1 & 2 & 1 & 34 & 21 & 1 & 0 \\
\hline 33 & 61 & 47 & 8 & 3 & 5 & 2 & 4 & 0 & 34 & 28 & 0 & 0 \\
\hline 34 & 64 & 39 & 1 & 4 & 7 & 0 & 3 & 1 & 26 & 18 & 0 & 0 \\
\hline 35 & 48 & 38 & 3 & 3 & 7 & 1 & 3 & 0 & 21 & 20 & 0 & 0 \\
\hline 36 & 43 & 35 & 8 & 2 & 6 & 0 & 4 & 0 & 20 & 21 & 0 & 0 \\
\hline 37 & 58 & 34 & 6 & 2 & 7 & 2 & 0 & 1 & 24 & 22 & 0 & 0 \\
\hline 38 & 46 & 39 & 1 & 1 & 5 & 0 & 1 & 0 & 25 & 18 & 0 & 0 \\
\hline 39 & 41 & 32 & 2 & 2 & 7 & 0 & 1 & 0 & 19 & 15 & 0 & 0 \\
\hline 40 & 53 & 30 & 6 & 1 & 8 & 1 & 3 & 0 & 26 & 13 & 0 & 0 \\
\hline 41 & 43 & 19 & 3 & 3 & 7 & 0 & 2 & 0 & 25 & 9 & 1 & 0 \\
\hline 42 & 46 & 35 & 3 & 2 & 4 & 0 & 0 & 0 & 23 & 16 & 0 & 0 \\
\hline 43 & 53 & 33 & 3 & 0 & 1 & 1 & 2 & 0 & 27 & 14 & 1 & 0 \\
\hline 44 & 38 & 25 & 2 & 2 & 4 & 0 & 2 & 0 & 22 & 11 & 0 & 0 \\
\hline 45 & 48 & 31 & 3 & 2 & 6 & 0 & 1 & 0 & 14 & 15 & 0 & 0 \\
\hline 46 & 45 & 33 & 1 & 0 & 7 & 0 & 0 & 0 & 19 & 13 & 1 & 0 \\
\hline 47 & 45 & 23 & 2 & 0 & 9 & 1 & 0 & 1 & 19 & 9 & 1 & 0 \\
\hline 48 & 42 & 29 & 0 & 1 & 5 & 1 & 0 & 0 & 22 & 15 & 0 & 0 \\
\hline 49 & 45 & 20 & 1 & 1 & 0 & 4 & 3 & 0 & 21 & 10 & 0 & 0 \\
\hline 50 & 41 & 22 & 4 & 0 & 10 & 0 & 0 & 0 & 16 & 9 & 1 & 0 \\
\hline 51 & 39 & 31 & 3 & 0 & 4 & 1 & 2 & 0 & 17 & 18 & 1 & 0 \\
\hline 52 & 40 & 27 & 5 & 2 & 2 & 1 & 0 & 0 & 21 & 8 & 0 & 0 \\
\hline 53 & 38 & 34 & 4 & 0 & 1 & 0 & 0 & 0 & 16 & 10 & 0 & 0 \\
\hline 54 & 41 & 28 & 4 & 2 & 3 & 2 & 0 & 0 & 15 & 10 & 0 & 1 \\
\hline 55 & 47 & 22 & 2 & 1 & 3 & 0 & 2 & 0 & 26 & 14 & 0 & 0 \\
\hline 56 & 39 & 14 & 2 & 0 & 7 & 0 & 0 & 0 & 17 & 6 & 0 & 0 \\
\hline
\end{tabular}

